\title{
Molecular Imaging to Plan Radiotherapy and Evaluate Its Efficacy
}

\author{
Robert Jeraj ${ }^{1,2}$, Tyler Bradshaw ${ }^{1}$, and Urban Simončič ${ }^{2}$ \\ ${ }^{1}$ School of Medicine and Public Health, University of Wisconsin, Madison, Wisconsin; and ${ }^{2}$ Faculty of Mathematics and Physics, \\ University of Ljubljana, Ljubljana, Slovenia
}

\begin{abstract}
Learning Objectives: On successful completion of this activity, participants should be able to describe (1) how to acquire high-quality molecular images for use in radiation therapy; (2) how molecular imaging can be used to plan radiotherapy and evaluate treatment efficacy; and (3) the limitations and challenges to widespread use of molecular imaging in radiation oncology.

Financial Disclosure: The authors of this article have indicated no relevant relationships that could be perceived as a real or apparent conflict of interest.

CME Credit: SNMMI is accredited by the Accreditation Council for Continuing Medical Education (ACCME) to sponsor continuing education for physicians. SNMMI designates each JNM continuing education article for a maximum of 2.0 AMA PRA Category 1 Credits. Physicians should claim only credit commensurate with the extent of their participation in the activity. For CE credit, SAM, and other credit types, participants can access this activity through the SNMMI website (http://www.snmmilearningcenter.org) through November 2018.
\end{abstract}

Molecular imaging plays a central role in the management of radiation oncology patients. Specific uses of imaging, particularly to plan radiotherapy and assess its efficacy, require an additional level of reproducibility and image quality beyond what is required for diagnostic imaging. Specific requirements include proper patient preparation, adequate technologist training, careful imaging protocol design, reliable scanner technology, reproducible software algorithms, and reliable data analysis methods. As uncertainty in target definition is arguably the greatest challenge facing radiation oncology, the greatest impact that molecular imaging can have may be in the reduction of interobserver variability in target volume delineation and in providing greater conformity between target volume boundaries and true tumor boundaries. Several automatic and semiautomatic contouring methods based on molecular imaging are available but still need sufficient validation to be widely adopted. Biologically conformal radiotherapy (dose painting) based on molecular imaging-assessed tumor heterogeneity is being investigated, but many challenges remain to fully exploring its potential. Molecular imaging also plays increasingly important roles in both early (during treatment) and late (after treatment) response assessment as both a predictive and a prognostic tool. Because of potentially confounding effects of radiation-induced inflammation, treatment response assessment requires careful interpretation. Although molecular imaging is already strongly embedded in radiotherapy, the path to widespread and all-inclusive use is still long. The lack of solid clinical evidence is the main impediment to broader use. Recommendations for practicing physicians are still rather scarce. ${ }^{18} \mathrm{~F}-\mathrm{FDG}$ PET/CT remains the main molecular imaging modality in radiation oncology applications. Although other molecular imaging options (e.g., proliferation imaging) are becoming more common, their widespread use is limited by lack of tracer availability and inadequate reimbursement models. With the increasing presence of molecular imaging in radiation oncology, special emphasis should be placed on adequate training of radiation oncology personnel to understand the potential, and particularly the limitations, of quantitative molecular

Received Aug. 2, 2015; revision accepted Sep. 8, 2015.

For correspondence or reprints contact: Robert Jeraj, Department of Medical Physics, University of Wisconsin, 1111 Highland Ave., Madison, WI 53705.

E-mail: rjeraj@wisc.edu

Published online Sep. 17, 2015.

COPYRIGHT (C 2015 by the Society of Nuclear Medicine and Molecular Imaging, Inc. imaging applications. Similarly, radiologists and nuclear medicine specialists should be sensitized to the special need of the radiation oncologist in terms of quantification and reproducibility. Furthermore, strong collaboration between radiation oncology, nuclear medicine/ radiology, and medical physics teams is necessary, as optimal and safe use of molecular imaging can be ensured only within appropriate interdisciplinary teams.

Key Words: PET/CT; molecular imaging; quantitative imaging; radiation therapy; target definition; treatment response assessment

J Nucl Med 2015; 56:1752-1765

DOI: 10.2967/jnumed.114.141424

$\mathbf{M}$ olecular imaging plays a central role in the management of radiation oncology patients. Although most uses and applications of molecular imaging in radiation oncology do not significantly differ from those in general oncology (e.g., diagnostic applications), there are some specific imaging requirements and uses that warrant separate discussion and review, particularly for planning and assessment of radiotherapy (Fig. 1).

Radiation therapy is a localized cancer treatment modality and, as such, requires accurate spatial localization of the tumor. Spatial localization has traditionally relied on anatomic imaging methods such as CT and MRI, but the added benefits of molecular imaging (e.g., increased sensitivity and specificity) make molecular imaging, and especially combined modalities such as PET/CT, particularly appealing. However, accurate spatial localization increases the complexity of the imaging procedure. For example, as patient (and tumor) position within the treatment system needs to be maintained during radiotherapy, the scanning position during molecular imaging procedures should be similarly maintained. These extra requirements increase the complexity of the process, not only to acquire molecular images but also to analyze them. With the recent interest in biologically conformal radiotherapy (dose painting), in which one would potentially target a spatially heterogeneous distribution of tumor resistance with variable levels of radiation dose, the requirements for molecular imaging quantification are further augmented. 


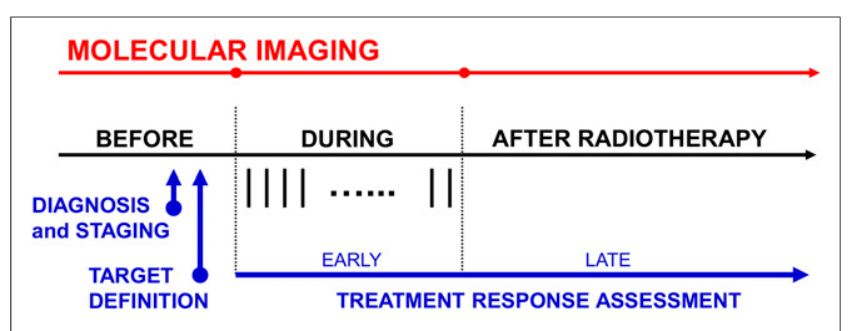

FIGURE 1. Use of molecular imaging in radiation oncology follows all steps of treatment process but with some specific challenges, particularly for defining treatment targets (e.g., requiring accurate spatial localization) and in treatment response assessment (e.g., requiring special attention to radiation-induced inflammation). Vertical bars during radiotherapy indicate individual treatment fractions.

${ }^{18} \mathrm{~F}-\mathrm{FDG}$ PET/CT has been the main imaging modality of choice for treatment response assessment. However, because of radiationinduced inflammation, the time points for treatment response assessment need to be carefully selected. Because inflammatory processes initiated during radiation therapy can persist for months after the therapy ends, both late (after treatment) and particularly early (during treatment) response assessment based on ${ }^{18} \mathrm{~F}-\mathrm{FDG}$ PET/CT requires complex interpretation. Solid tumors that are commonly treated with radiotherapy or chemoradiotherapy show variable resistance to therapy, ranging from very sensitive tumors (e.g., lymphoma, seminoma) to highly resistant tumors (e.g., melanoma and glioblastoma), with most squamous cell carcinomas and adenocarcinomas being in the intermediate zone. For resistant tumors, changes in tumor glucose metabolic activity may be small and occur only late during the course of radiotherapy. Fortunately, several alternative PET radiotracers and different modalities for molecular imaging exist, most notably $3{ }^{\prime}-{ }^{18}$ F-fluoro-3'-deoxy-L-thymidine ( $\left.{ }^{18} \mathrm{~F}-\mathrm{FLT}\right)$, a surrogate of tumor proliferation, and various MRI techniques, which are particularly applicable for assessment of brain tumors.

This article provides a comprehensive and contemporary overview of molecular imaging applications in radiation therapy, particularly for target definition and treatment response assessment. Specific quantitative imaging requirements for use in radiation therapy, and potential confounding artifacts that limit image interpretation, will be highlighted. Future perspectives for full exploration of molecular imaging, particularly for biologically conformal applications of radiotherapy, will be discussed.

\section{QUANTITATIVE IMAGING FOR RADIATION THERAPY}

Molecular images should be of high quality for effective application in radiotherapy target delineation and treatment response assessment. The quality of molecular images depends on a combination of multiple factors, including patient preparation, technologist training, imaging protocol design, scanner technology, software algorithms, and data analysis methods. Several guidelines are available that provide recommendations on imaging procedures for ${ }^{18}$ F-FDG $(1,2)$, as well as for other PET radiotracers $(3,4)$. Practice guidelines for certain functional MRI procedures have also been suggested by the American College of Radiology (5). Molecular imaging for radiation therapy applications, however, requires an additional level of reproducibility and image quality beyond what is required for diagnostic imaging. This section will discuss the general steps to acquiring high-quality molecular images for use in radiation therapy planning and treatment response evaluation, with the focus on PET/CT but also briefly discussing other molecular imaging modalities, such as MRI.

\section{Image Acquisition}

It is important that patients undergo similar preparations before imaging and before receipt of each fraction of radiation therapy. For example, for abdominal tumors, fasting before imaging and treatment increases the likelihood that the stomach and bowels are the same size during treatment planning as they will be for each treatment session. For ${ }^{18} \mathrm{~F}-\mathrm{FDG}$ PET imaging, fasting also helps to keep blood glucose levels within acceptable ranges for imaging. Blood glucose levels should be checked before ${ }^{18} \mathrm{~F}-\mathrm{FDG}$ injection, and the scan should be rescheduled if levels are outside a predetermined range (2).

Molecular imaging for radiation therapy planning requires equipment and procedures additional to those typically used for diagnostic imaging. Unlike diagnostic images, images for radiation therapy planning will eventually need to be coregistered with treatment-planning CT images. Reliable target delineation is contingent on the accuracy of registration between the functional image and the planning CT image. As such, molecular imaging acquisitions for radiation therapy planning need to follow principles similar to those recommended for planning CT (or simulation CT) acquisitions (6).

The patient should be positioned and immobilized during image acquisition in the same manner as during receipt of each fraction of therapy. Because flat-top couches are used for radiation therapy delivery to ensure repeatable positioning, a flat-top table should be placed on top of the patient table. Any immobilization devices, padding, or bolus material should be in place during the scan. For nuclear medicine, placement of positioning equipment outside the transaxial imaging field of view but within the scanner bore should be avoided, as it can lead to attenuation artifacts (7). Scanners with large bores are preferred to accommodate the extra equipment. Positioning for functional MRI can be more challenging, depending on the tumor site (8). For example, for head and neck cancer, personalized masks are often used to ensure reproducible positioning and immobilization, but these masks often do not fit inside standard head coils. Furthermore, MRI bores are often smaller than CT bores, potentially limiting the use of some positioning devices. In these cases, creative solutions may be necessary (9). In addition to the internal positioning lasers included with imaging systems, it is preferable to have mobile external lasers for patient marking/ tattooing and positioning, similar to those used during CT simulation. The positioning of the lasers should be precise and maintained at a known spatial relationship to the image center, so that patients can be marked in a way that will ensure repeatable positioning at subsequent treatment sessions. The alignment of the external laser should be tested for accuracy; such quality assurance tests have been described by the American Association of Physicists in Medicine (AAPM) task group 66 (6).

For PET/CT imaging, there are different options for acquiring the CT component of the scan. Attenuation and scatter correction for PET image reconstruction can typically be performed using either low-dose CT or high-quality diagnostic CT. The preference is to acquire a single high-quality CT scan together with the PET scan, which can then be used for treatment planning. In this case, no additional image registration is needed to align the PET image and the planning CT image. Treatment-planning CT, however, is sometimes performed with intravenous contrast material. Unless corrected for, contrast-enhanced CT can cause the PET voxel values in regions of high contrast density to be increased when the scan is used for attenuation correction (10). In these cases (or when the planning CT scan has been acquired separately), an additional lowdose CT scan should be acquired together with the PET scan. This 
low-dose CT scan can be used for attenuation and scatter correction but is not suitable for treatment planning. If contrast-enhanced CT is to be performed during the PET/CT examination, it should occur after both the attenuation $\mathrm{CT}$ and the PET acquisitions. A promising alternative to PET/CT imaging, which will become more prevalent in the future, is PET/MRI, in which pseudo CT images are created and used for PET attenuation correction (11) and potentially also for radiotherapy planning (12). The challenge of pseudo CT generation is that the MRI intensity value of a single voxel cannot be uniquely mapped into the $\gamma$-ray attenuation coefficient. Although several methods to improve the accuracy of pseudo CT mapping (e.g., registered atlas CT) have been developed (11), these have yet to be thoroughly validated for use in radiation therapy planning.

\section{Registration}

When the planning CT image is not already registered to the functional images, the two image coordinate systems need to be aligned. Rigid registration algorithms rotate and translate two images to maximize the spatial similarity of their intensity values. Most modern image-analysis software packages include methods for performing rigid registration. For PET, the CT image from the PET/CT acquisition is typically registered to the planning CT image, and the resulting spatial transformation is then applied to the respective PET image. Voxel sizes for PET images are larger than CT voxel sizes and, depending on the software, may need to be upsampled before PET can be used for target delineation. Unless nearest-neighbor resampling is used, this resampling step will alter the quantitative SUVs; therefore, quantitative image analysis for treatment response assessment should be performed before the PET image registration. For functional MRI, anatomic MRI sequences such as volumetric T1-weighted imaging should also be acquired during imaging so that MRI and CT images can be coregistered. Special software may be required to register anatomic MRI and CT images, as the imaging values for different tissues are inherently different between the two imaging modalities.

In many cases, patient positioning will not be identical in the molecular images and in the planning CT image. This issue can make rigid registration difficult and can occasionally cause algorithms to converge to strange solutions (results should always be checked). One option, if the software allows it, is to crop the template image, leaving only the regions of interest to be registered. Another option is to use deformable registration algorithms. Like rigid registration, deformable registration algorithms maximize the similarities between two images but allow for morphologic changes beyond rotation and translation. These algorithms ultimately warp the template image to match the reference image. There are several deformable registration algorithms, each with different similarity measures or regularization constraints. Because the resulting solution will differ depending on the algorithm used, an algorithm should not be arbitrarily chosen (13). Quality assurance processes for image registration have been proposed (14), and an upcoming report from task group 132 of the AAPM will further describe the proper use and quality assurance of image registration algorithms.

\section{Motion}

Patient motion during imaging causes the image to be blurred over the path of motion, elongating target volumes. Motion also affects image quantification, effectively reducing image intensity values (15). Certain motions, such as breathing, cannot be avoided during treatment and will affect imaging of the lungs, liver, esophagus, pancreas, breast, prostate, kidneys, and other organs. Lung motion amplitudes are case-dependent but usually range between 0 and $30 \mathrm{~mm}$ in the superior-inferior direction, with an average of around $10 \mathrm{~mm}(16)$.

The degree to which motion should be compensated for during imaging depends on the degree to which motion will be accounted for during treatment. In other words, motion management for imaging should be coupled to motion management strategies during radiation delivery. In the case of PET, the simplest strategy would be to apply no motion correction to PET images, as both PET imaging and radiation therapy delivery encompass all phases of respiratory motion. Likewise, slow CT imaging can be used to create a phase-averaged CT image (17). Not accounting for motion during planning and radiation therapy delivery, however, can result in an unnecessary dose to nearby healthy organs.

There are several methods to reduce or account for respiratory motion during imaging and radiation therapy delivery. A detailed description of these methods is beyond the scope of this review but has been published elsewhere (16). These methods include shallow or tidal breathing to limit motion amplitude, respiratory gating $(16,18)$, and real-time tumor tracking $(19,20)$. In any case, the type of image acquisition should be closely matched to the type of radiation treatment delivery (e.g., 4-dimensional [4D] PET/CT together with real-time radiation delivery tracking).

\section{Uncertainties}

Uncertainties in molecular imaging arise from technical factors (e.g., scanner calibration), physical factors (e.g., positron range), biologic factors (e.g., patient metabolism), and analytic factors (e.g., inconsistent image processing) $(21,22)$. Some of these uncertainties can be controlled or minimized through careful study design and quality assurance procedures (Table 1 provides examples specific to ${ }^{18} \mathrm{~F}$-FDG PET). Understanding the limitations and uncertainties of molecular imaging is necessary to its proper implementation in radiation oncology.

For PET imaging, one limitation is its spatial resolution. There are many factors that affect PET spatial resolution, but in general, PET-avid lesions with diameters less than 5-10 $\mathrm{mm}$ are unlikely to be discernible from background in a typical clinical PET image (23). Consequently, small lesions, some positive lymph nodes, sharp intratumor heterogeneities, and microscopic tumor extensions may not be resolved in a PET image. The limited spatial resolution of PET has implications for its use in target volume delineation and treatment response assessment.

Uncertainties in molecular image quantification will propagate into uncertainties in treatment response assessment. Quantitative imaging for treatment response assessment requires proper calibration of the scanner equipment (including the dose calibrator for nuclear medicine) at acceptance testing and during routine maintenance. A detailed quality assurance plan, including daily, quarterly, and annual calibrations, is necessary to ensure the reliability and consistency of the scanner equipment $(24,25)$. For MRI, quality assurance procedures that minimize geometric distortion caused by gradient field nonlinearity or static field inhomogeneity are especially important. Even with properly calibrated equipment, however, biologic variability and statistical noise cause substantial uncertainties in molecular imaging. For example, test-retest studies with ${ }^{18}$ F-FDG PET imaging suggest that biologic and statistical uncertainties contribute to an overall uncertainty (coefficient of variation) in $\mathrm{SUV}_{\max }$ of about $10 \%-15 \%(26,27)$. Even the position of a lesion relative to the detector array geometry can cause fluctuations in PET SUV for small lesions (28). 
TABLE 1

Uncertainties and Quality Control Measures for PET/CT in Radiation Therapy Planning

\begin{tabular}{|c|c|c|c|}
\hline Category & Procedure & Uncertainties & Quality control \\
\hline \multirow[t]{5}{*}{ Scanning protocol } & Patient preparation & Metabolism levels ( $\left.{ }^{18} \mathrm{~F}-\mathrm{FDG}\right)$ & Limit physical activity \\
\hline & & Blood glucose levels ( $\left.{ }^{18} \mathrm{~F}-\mathrm{FDG}\right)$ & $\begin{array}{l}\text { Measure fasting blood glucose with } \\
\text { exclusion criteria }\end{array}$ \\
\hline & & Bowel size/positioning & Use fasting protocol \\
\hline & $\begin{array}{l}\text { Radiotracer } \\
\text { injection }\end{array}$ & Residual activity in syringe & Measure/correct for residual activity \\
\hline & & Decay correction errors & Synchronize scanner clock \\
\hline \multirow[t]{6}{*}{ Acquisition } & $\begin{array}{l}\text { Patient } \\
\text { positioning }\end{array}$ & $\begin{array}{l}\text { Spatial offset between PET and } \\
\text { treatment-planning CT }\end{array}$ & $\begin{array}{l}\text { Ensure consistent patient positioning } \\
\text { using identical positioning devices }\end{array}$ \\
\hline & & $\begin{array}{l}\text { Quantitative uncertainties from } \\
\text { attenuating objects }\end{array}$ & $\begin{array}{l}\text { Avoid placing objects outside image } \\
\text { field of view }\end{array}$ \\
\hline & Scanning & Patient motion & $\begin{array}{l}\text { Implement motion management } \\
\text { strategies }\end{array}$ \\
\hline & & $\begin{array}{l}\text { Attenuation correction uncertainties } \\
\text { from iodine contrast material }\end{array}$ & $\begin{array}{l}\text { Acquire separate low-dose CT scan or } \\
\text { apply corrections }\end{array}$ \\
\hline & & Equipment failure or electronic drift & $\begin{array}{l}\text { Calibrate detector and equipment } \\
\text { frequently }\end{array}$ \\
\hline & & $\begin{array}{l}\text { Increased SUV because of longer } \\
\text { uptake period }\end{array}$ & Apply strict protocol for uptake period \\
\hline \multirow[t]{2}{*}{ Reconstruction } & Reconstruction & $\begin{array}{l}\text { Selection of optimal image } \\
\text { reconstruction method/parameters }\end{array}$ & $\begin{array}{l}\text { Benchmark algorithms using phantoms } \\
\text { (task-specific) }\end{array}$ \\
\hline & & $\begin{array}{l}\text { Randoms, scatter, attenuation, } \\
\text { detector sensitivity, and } \\
\text { partial-volume effect }\end{array}$ & $\begin{array}{l}\text { Apply appropriate calibrations and } \\
\text { corrections }\end{array}$ \\
\hline \multirow[t]{6}{*}{ Analysis } & Segmentation & $\begin{array}{l}\text { Differentiation of normal tissue } \\
\text { and tumor uptake }\end{array}$ & $\begin{array}{l}\text { Know radiotracer's normal } \\
\text { biodistribution }\end{array}$ \\
\hline & & Segmentation uncertainties & $\begin{array}{l}\text { Develop segmentation protocol; } \\
\text { benchmark algorithms with } \\
\text { phantoms }\end{array}$ \\
\hline & & $\begin{array}{l}\text { Limited spatial resolution and } \\
\text { sensitivity }\end{array}$ & Include margins \\
\hline & Quantification & Quantitative accuracy & $\begin{array}{l}\text { Calibrate PET scanner to dose } \\
\text { calibrator }\end{array}$ \\
\hline & & $\begin{array}{l}\text { Selection of relevant quantitative } \\
\text { measures }\end{array}$ & $\begin{array}{l}\text { Compare semiquantitative metrics with } \\
\text { kinetic analysis-derived parameters; } \\
\text { consult literature }\end{array}$ \\
\hline & & $\begin{array}{l}\text { Quantitative differences between } \\
\text { scanners/institutions }\end{array}$ & Quantitatively harmonize scanners \\
\hline \multirow[t]{2}{*}{ Treatment planning } & Target definition & Registration errors & $\begin{array}{l}\text { Benchmark algorithms using physical } \\
\text { or digital phantoms; crop images }\end{array}$ \\
\hline & & Motion & $\begin{array}{l}\text { Use same motion management method } \\
\text { as was used during imaging }\end{array}$ \\
\hline
\end{tabular}

Similar uncertainties exist for all other molecular imaging modalities, which require specific quality control measures.

There are also uncertainties on how to best extract meaningful quantitative imaging biomarkers from molecular images. In PET, the semiquantitative SUV is easily calculated by normalizing the measured radioactivity concentration in an image voxel by the ratio of the patient's injected activity to body weight — either total body weight or lean body mass. Both the $\mathrm{SUV}_{\text {mean }}$ and the $\mathrm{SUV}_{\max }$ of a region of interest are typically reported. However, depending on the application and radiotracer used, SUV may not represent a reliable measure of the biologic process of interest and can be very sensitive to the conditions of the acquisition, reconstruction, and analysis. In 
these cases, dynamic imaging with kinetic analysis may be necessary to understand the tracer kinetics and extract the most biologically relevant parameters. Dynamic scans are much more challenging to perform and analyze than static scans.

In MRI, similar challenges in image quantification exist. For example, it is becoming increasingly common for apparent diffusion coefficient (ADC) from diffusion-weighted (DW) MRI to be measured in clinical examinations, but standardized protocols for acquisition and analysis of DW MR images are lacking, especially across vendors (29). This lack of standardization also applies to perfusion MRI, which models and calculates kinetic parameters relating to blood flow. Standards for appropriate uses and analyses of quantitative imaging biomarkers, including proper characterization of their uncertainties, are being developed by the Quantitative Imaging Biomarkers Alliance (30).

Quantitative PET image values are highly sensitive to the algorithm used to reconstruct the images (31). With iterative reconstruction algorithms (which have become standard in clinical PET imaging) and a growing library of image correction methods (e.g., point-spreadfunction modeling), there are hundreds of possible combinations of reconstruction parameters. Furthermore, the optimal reconstruction method may depend on the region of interest (e.g., chest vs. brain). It is therefore incumbent on an institution's nuclear medicine physicians, physicists, or technologists to determine the reconstruction method that optimizes image quality for a particular PET scanner. This generally involves scanning a PET image-quality phantom, exploring several different reconstructions, and finding the set of parameters that offers the best trade-off between spatial resolution and image noise. Furthermore, as different PET scanners can have substantial differences in image quality and quantitative accuracy, image reconstruction parameters can be tuned such that the different PET scanners involved in a multicenter study produce comparable image quality. This process of scanner harmonization can improve the statistical power of multicenter clinical trials investigating imaging biomarkers (32).

Overall, many uncertainties in molecular imaging and in its application to radiation oncology can be minimized using a detailed and unambiguous protocol for acquisition and image analysis. One such protocol is the ${ }^{18} \mathrm{~F}$-FDG PET imaging protocol developed by the Uniform Protocols for Imaging in Clinical Trials working group (33). Strict adherence to protocols ensures that for baseline and follow-up imaging, identical procedures will be followed for patient preparation, patient immobilization, radiotracer or contrast injection, acquisition settings, image reconstruction/corrections, image processing, and image analysis. Minimizing these quantitative imaging uncertainties will allow for more precise quantification of treatment response (34).

\section{MOLECULAR IMAGING FOR TARGET DEFINITION}

Uncertainty in target definition is arguably the greatest challenge facing radiation oncology. Recent technologic advances in radiation delivery and dosimetry allow for precise and conformal delivery of dose to patients. Exactly where that dose should be delivered, on the other hand, is still not clear. The impact that uncertainty in target volume delineation has on patient dosimetry is almost an order of magnitude greater than the impact of tumor motion $(16,35)$. Perhaps the greatest impact that molecular imaging can have in radiation oncology is in reducing interobserver variability in target volume delineation and in bringing about greater conformity between target volume boundaries and true tumor boundaries. An upcoming report from task group 211 of the AAPM will further describe the proper use of ${ }^{18} \mathrm{~F}$-FDG PET/CT for target definition.

\section{Manual Tumor Segmentation}

Currently, the most common method for molecular imaging-based gross tumor volume delineation is manual segmentation. A prerequisite for all molecular imaging-based segmentation methods is an understanding of the normal biologic processes that will be measured in the images, so that normal tissue is not mistaken for diseased tissue during segmentation. Potential sources of false-positives and falsenegatives should be well understood. For example, in the case of ${ }^{18}$ F-FDG PET, brown adipose tissue, granulous tissue, areas of inflammation, and muscle often have elevated levels of uptake and can be mistaken for tumor $(1,36)$. PET images should be interpreted by nuclear medicine physicians and MR images by radiologists before being used for radiation therapy purposes so that, if necessary, previously unknown lesions can be detected and potential image artifacts can be identified.

After image registration, the molecular and the anatomic images should be fused by the visualization software (37). All available information should be used for defining the target volume. Manual segmentation methods, however, are known to suffer from interand intraobserver variability in target volume delineation. To reduce this variability, it is recommended that institutions develop a strict delineation protocol that describes exactly how the tumor should be visualized (e.g., window level and color settings) and details any other parameters that can affect the physician's choice of contouring (38). Because of the significant inter- and intraobserver variability, manual segmentation is generally inferior to automatic and semiautomatic segmentation and as such is discouraged. However, it will take some time for the manual segmentation to be entirely replaced by automatic and semiautomatic segmentation tools, which still require more rigorous clinical validation.

If DW MRI is used for tumor segmentation, special attention should be paid to the potential for spatial distortions in the ADC maps. Studies have found that substantial geometric distortions can occur in DW MR images, even on the order of centimeters (39). Such distortions, both global and local, can also occur for other imaging sequences, including sequences used for perfusion MRI. If not accounted for, these distortions can substantially affect the accuracy of the target volume delineation.

\section{Automatic and Semiautomatic Tumor Segmentation}

Computer algorithms that automate tumor volume segmentation based on molecular images can improve workflow and reduce physician variability in target definition. In PET, the most common method for automatic segmentation is thresholding based on SUV. There are different ways by which thresholding can be performed. A threshold based on $\mathrm{SUV}_{\text {max }}$ is the most commonly used method and usually the most simple. The threshold value for ${ }^{18} \mathrm{~F}-\mathrm{FDG}$ PET is often set at around $40 \%$ of $\mathrm{SUV}_{\max }$ but varies from $20 \%$ to $50 \%$. Other types of thresholding include using a fixed SUV threshold (e.g., SUV $\geq 2.5$ (40)) or using a background-subtracted threshold (41). A clear disadvantage of thresholding is the uncertainty about which threshold is optimal, which can vary depending on the scanner hardware, reconstruction and acquisition parameters, presence of motion, tumor size, and patient biology (42). Furthermore, thresholding cannot distinguish normal uptake from disease, and results will need to be corrected manually, preferably by an experienced nuclear medicine physician. 
Numerous advanced automatic and semiautomatic PET segmentation algorithms have been developed $(43,44)$. Broadly, these can be categorized as iterative/adaptive methods, statistical modeling methods, machine learning-based methods, and image filter-based methods (e.g., using gradients or texture features). Currently, it remains unclear which methods perform best and how best to assess the performance of different algorithms. Various performance evaluation methods have been developed for testing segmentation algorithms $(44,45)$. It is recommended that institutions thoroughly evaluate segmentation algorithms, including any tuning parameters, and benchmark their performance against both phantom and clinical images before clinical implementation. Even when automatic and semiautomatic tools are used, manual review of the contours is highly recommended.

For brain tumor segmentation, the utility of ${ }^{18} \mathrm{~F}$-FDG PET is limited by high background levels of ${ }^{18}$ F-FDG uptake in healthy brain tissue. Other radiotracers have been shown to perform better in the identification and delineation of brain tumors. For example, the amino acid radiotracers $O-\left(2-{ }^{18} \mathrm{~F}\right.$-fluoroethyl)-L-tyrosine and L-[methyl- $\left.{ }^{11} \mathrm{C}\right]$-methionine are taken up by cancer cells because of overexpression of amino acid transporters (46,47). 3,4-dihydroxy$6-{ }^{18} \mathrm{~F}$-fluoro-L-phenylalanine $\left({ }^{18} \mathrm{~F}\right.$-DOPA) is another amino acid PET radiotracer that has produced promising results (48). MRI, however, remains the standard for delineation of most brain tumors. Other tumor sites may also benefit from the use of nonstandard PET radiotracers for target definition, such as $16 \alpha-{ }^{18} \mathrm{~F}-$ fluoro-17 $\beta$-estradiol in breast cancer, and somatostatin-analogs DOTATOC and DOTATATE for neuroendocrine tumors.

\section{Nodal Involvement}

The ability of PET imaging to detect involved lymph nodes that appear benign on CT images has been demonstrated (49). However, its improvement over CT imaging for nodal detection is dependent on the tumor site. A series of review papers has been published on PET for radiation treatment planning for various tumor sites, including the brain (50), head and neck (51), lung (52), gastrointestinal tract (53), prostate (54), and cervix/ endometrium (55). For some situations, such as mediastinal lymph node staging for lung cancer, the sensitivity of ${ }^{18} \mathrm{~F}-\mathrm{FDG}$ $\mathrm{PET} / \mathrm{CT}$ appears to be superior to $\mathrm{CT}$ alone at detecting involved lymph nodes (52). In others, such as colorectal cancer, PET does not perform as well (56). It remains to be seen whether PET/MRI scanners will improve nodal detection, particularly in some anatomic sites such as the abdomen.

\section{Tumor Boosting}

One appealing future application of molecular imaging in radiation therapy planning is in the delineation of biologic tumor subvolumes for dose escalation. This method has been termed biologically conformal radiation therapy, or dose painting (57). The rationale for dose painting comes from the fact that tumors are biologically heterogeneous in composition and often show nonuniform patterns of response to radiation therapy $(58,59)$. Molecular imaging may be able to identify spatial patterns of radioresistance, which can be used to guide and shape the dose distribution. Indirect evidence of this principle comes from studies that have found molecular imaging biomarkers to correlate with patient outcome after radiation therapy $(60,61)$. Possible biologic targets include tumor hypoxia (measured with PET hypoxia radiotracers or with dynamic contrast-enhanced [DCE] MRI), cellularity (measured with ${ }^{18}$ F-FDG PET or DW MRI), and others. Identifying effective and robust imaging-based targets for dose painting is currently an ongoing research problem $(61,62)$. Dose painting can be applied either on a region-of-interest level (dose painting by contours) or on a voxel level (dose painting by numbers), in which each tumor voxel receives a unique dose prescription proportional to the voxel's image intensity value (63). Studies have demonstrated the feasibility of creating and delivering dose-painting plans_-both subvolume boosting and voxel-based dose painting-using existing clinical software and therapy systems (64).

Dose painting has yet to be validated as an effective treatment option, but clinical studies have begun to investigate the efficacy of dose painting. Studies have been performed on the brain using ${ }^{18} \mathrm{~F}-\mathrm{FDG}(65)$ and $O-\left(2-{ }^{18} \mathrm{~F}\right.$-fluoroethyl)-L-tyrosine PET (66), on head-and-neck tumors using ${ }^{18}$ F-FDG PET (67-69), on prostate tumors using ${ }^{18} \mathrm{~F}$-fluorocholine PET (70), and on lung tumors using ${ }^{18}$ F-FDG PET (71). Further clinical studies are ongoing.

\section{Normal-Tissue Sensitivity}

The potential for using molecular imaging to discriminate radiosensitive tissue from radioresistant tissue in tumors may be equally valuable when applied to the surrounding normal tissue. Certain regions in an organ, particularly the lung, appear to be more sensitive to radiation therapy than other regions in the same organ. Or some regions may be more functional than other regions and therefore more important to spare. For example, in ${ }^{18} \mathrm{~F}$-FDG PET imaging of the lungs, studies have found that regions of uptake before radiation therapy are more likely to experience radiationinduced toxicity after radiation therapy (72). Ventilation imaging may identity lung regions that are blocked-either by obstructive lung disease or by tumor burden — and may contribute less to overall lung function than healthy, functioning lung. Information on functional lung can be acquired through a variety of imaging methods. For MRI, hyperpolarized gases or gadolinium aerosol can be used in combination with serial imaging to produce 4D images of lung ventilation (73). Ventilation maps can also be derived from 4D CT imaging, in which voxel Hounsfield units correlate with the fraction of air in the voxel volume (74). In SPECT, ${ }^{99 m}$ Tc-labeled macroaggregated albumin can also be used to create $3 \mathrm{D}$ ventilation maps (75). The feasibility of incorporating lung ventilation maps into treatment planning for conformal avoidance has been demonstrated (76). Although promising, the clinical benefit of using functional lung images for conformal avoidance has yet to be validated.

Overall, there are many potential uses of molecular imaging in target definition for radiation therapy. The various methods by which molecular imaging can be used for target definition and their respective degrees of complexity are outlined in Table 2. Considering the extensive ongoing clinical research and continuous technologic advances, it is likely that the methods presently considered to be advanced will soon become routine practice.

\section{MOLECULAR IMAGING FOR TREATMENT RESPONSE ASSESSMENT}

In radiation oncology, the time point at which treatment response is assessed will depend on the purpose of the assessment (Fig. 1). Early assessment-during the course of radiotherapyserves as an early predictor of treatment outcome and potentially allows the therapy to be adapted in order to maximize its benefit. Late assessment-after the radiotherapy has been completedserves as a late predictor of treatment outcome in order to guide patient care after radiotherapy. Anatomic changes visible on CT or MRI, which have traditionally been used to assess treatment response, typically occur slowly over the course of weeks and 
TABLE 2

Methods to Incorporate Molecular Images into Radiation Therapy Planning and Their Respective Degrees of Complexity

\begin{tabular}{lllll}
\hline Complexity & Registration & Segmentation & Target definition & Motion management \\
\hline Basic & Manual alignment & Manual & Boundary definition & None (phase-averaged) \\
& Rigid/affine & Threshold-based & Subvolume boost & Gated imaging and delivery \\
Advanced & Deformable & Automatic algorithms & Voxelwise dose painting & 4D imaging and delivery \\
\hline
\end{tabular}

months after the therapy (77), whereas with molecular imaging treatment response can potentially be assessed much earlier.

The potential of using changes in SUV on ${ }^{18} \mathrm{~F}-\mathrm{FDG}$ PET to assess treatment response earlier was recognized by the European Organization for Research and Treatment of Cancer in its recommendations (78). Later, frameworks for PET-based therapy response evaluation were drafted by the National Cancer Institute (79) and Wahl et al., ultimately resulting in the PET Response Criteria in Solid Tumors (PERCIST) (80). Initially, ${ }^{18} \mathrm{~F}-\mathrm{FDG}$ PET-based therapy response assessment was used for only chemotherapy. A limitation of ${ }^{18}$ F-FDG PET-based therapy response assessment in radiation oncology is the high ${ }^{18} \mathrm{~F}$-FDG avidity of normal tissue surrounding the tumor because of inflammation, which builds up late during or early after the completion of radiotherapy. In contrast to inflammatory changes in normal tissue, metabolic activity in tumors decreases progressively during radiotherapy, leading to a relatively narrow window of opportunity to extract information from molecular imaging — when there are still enough viable tumor cells but before the surrounding inflammatory changes start to dominate (typically within the first 2-3 wk).

The problem of inflammatory changes in normal tissue during and after radiotherapy, which hinders early ${ }^{18} \mathrm{~F}-\mathrm{FDG}$ PET/CT-based assessment of radiotherapy response, is obviously ${ }^{18} \mathrm{~F}-\mathrm{FDG}-$ specific. Other types of molecular imaging techniques, such as PET/CT with other radiotracers (e.g., ${ }^{18} \mathrm{~F}-\mathrm{FLT}$ ) or various MRI techniques, typically avoid this problem. However, ${ }^{18} \mathrm{~F}-\mathrm{FDG} \mathrm{PET} / \mathrm{CT}$ is by far the most established molecular imaging technique, as is evident from their being no similar response assessment guidelines established yet for other types of molecular imaging techniques.

\section{Prognostic Role of Molecular Imaging in Radiation Therapy}

High clinical availability and wide applicability are why ${ }^{18} \mathrm{~F}-\mathrm{FDG}$ $\mathrm{PET} / \mathrm{CT}$ is most commonly investigated as a prognostic and predictive imaging biomarker in radiation oncology. Relative changes in ${ }^{18}$ F-FDG SUVs are commonly investigated for being representative of clinical response, as suggested in the guidelines of the European Organization for Research and Treatment of Cancer and the National Cancer Institute, as well as PERCIST, for the measurement of treatment response (78-80). These guidelines also provide criteria for classifying patients into various response categories (complete response, partial response, stable disease, progressive disease). The response thresholds have not been generally validated in larger clinical trials and therefore serve mostly as recommended guidelines for standardized reporting. In addition, ${ }^{18} \mathrm{~F}-\mathrm{FDG}$ PET/CTbased therapy response assessment requires proper selection and control of some factors that are highly important for therapy response assessment. One of them is the timing of sequential ${ }^{18} \mathrm{~F}-\mathrm{FDG}$ PET/CT imaging for response assessment. Because of the dynamic nature of inflammatory and tumor-response processes, the timing of imaging relative to the treatment schedule has a profound effect on how early it is possible to assess treatment response.
Some key studies representing the current evidence for various tumor types are highlighted as follows.

Lung Cancer. In lung cancer, clinical outcome has been correlated with the metabolic tumor response rate assessed after the end of radiotherapy. For example, overall survival at 9 mo in 102 patients with non-small cell lung cancer (NSCLC) of various stages has been correlated with the metabolic tumor response rate assessed $70 \mathrm{~d}$ after the end of radiotherapy (81). Furthermore, various small clinical studies have demonstrated that ${ }^{18} \mathrm{~F}-\mathrm{FDG}$ PET/CT imaging during the course of radiotherapy can predict late metabolic response or clinical outcome in NSCLC patients $(82,83)$. Timing in sequential ${ }^{18}$ F-FDG PET imaging for early response assessment is extremely important, as has been clearly demonstrated by van Baardwijk et al., who have shown that ${ }^{18} \mathrm{~F}-\mathrm{FDG}$ PET $\mathrm{SUV}_{\max }$ in nonresponding NSCLC patients increased in the first week of radiotherapy and then decreased in the second week of radiotherapy and after radiotherapy (84). In contrast, changes in $\mathrm{SUV}_{\max }$ for responding patients were negligible during radiotherapy and notably negative after radiotherapy. ${ }^{18} \mathrm{~F}$-FDG uptake and functional volume for both primary tumors and lymph nodes in NSCLC generally decrease during the course of radiotherapy, roughly linearly with time or dose, suggesting that ${ }^{18}$ F-FDG PET/CT images can be acquired during radiotherapy without artifacts that hamper image interpretation and quantification (85).

Head and Neck Cancer. In head and neck cancer, the first initiative to assess response after radiotherapy with ${ }^{18} \mathrm{~F}$-FDG PET/CT dates back almost 3 decades (86). Currently, ${ }^{18}$ F-FDG PET/CT is widely accepted for assessing response after radiotherapy or chemoradiotherapy, with imaging typically performed 3-6 mo after completion of radiotherapy (87-89). Reports on using ${ }^{18}$ F-FDG for early response assessment during radiotherapy or chemoradiotherapy are much less frequent than reports on late ${ }^{18} \mathrm{~F}-\mathrm{FDG}$ PET/CT-based response assessment. Generally, reports on early assessment agree that ${ }^{18}$ F-FDG PET/CT during chemoradiotherapy may help differentiate responders from nonresponders, but these results are not yet reliable enough to replace posttherapy ${ }^{18} \mathrm{~F}$-FDG PET/CT evaluation (90).

Rectal Cancer. In rectal cancer, the most common therapy for early and locally advanced stages is radical surgery, which is usually preceded by preoperative radiotherapy or chemoradiotherapy. The surgical approach depends heavily on assessing the success of preoperative chemoradiotherapy. It has been shown that pathologic response to preoperative chemoradiotherapy can be reliably evaluated by ${ }^{18} \mathrm{~F}-\mathrm{FDG}$ PET/CT during chemoradiotherapy (91). Similarly, when ${ }^{18} \mathrm{~F}$-FDG PET/CT is performed early, between 1 and 2 wk after the onset of preoperative chemoradiotherapy, it has been shown to be highly accurate in predicting response in patients with locally advanced rectal cancer (92). In addition, posttherapeutic response assessment with ${ }^{18} \mathrm{~F}$-FDG PET has also been thoroughly studied (93).

Esophageal Cancer. Late response assessment with ${ }^{18} \mathrm{~F}-\mathrm{FDG}$ $\mathrm{PET} / \mathrm{CT}$ during neoadjuvant treatment is suggested to be a significant 


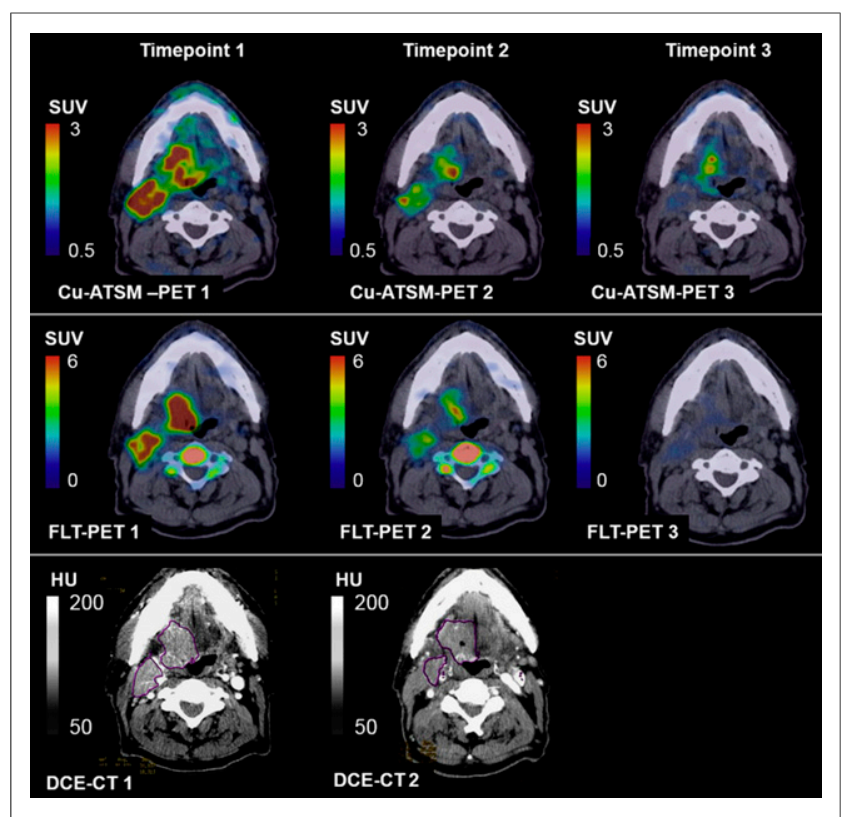

FIGURE 2. Multimodality multitracer molecular images of ${ }^{61} \mathrm{Cu}$-diacetylbis(N4-methylthiosemicarbazone) (CU-ATSM) PET, ${ }^{18} \mathrm{~F}$-fluorothymidine (FLT) PET, and DCE CT in patient before bevacizumab monotherapy (time point 1), after $3 \mathrm{wk}$ of bevacizumab (time point 2), and after 1-2 wk of chemoradiation therapy (time point 3), indicating potential of molecular imaging to assess complex radiation treatment regimens. (Reprinted with permission of (116).)

prognostic predictor of disease-free and overall survival in locally advanced esophageal and esophagogastric junction cancer (94). Early response assessment with ${ }^{18} \mathrm{~F}-\mathrm{FDG} \mathrm{PET} / \mathrm{CT}$ is not considered a reliable prognostic predictor in esophageal cancer (95).

Cervical Cancer. In locally advanced cervical cancer, the generally accepted method of response assessment is ${ }^{18} \mathrm{~F}$-FDG PET/CT 3 mo after the completion of concurrent chemoradiotherapy; reliable longterm prognostic information can be obtained (96). Despite the high predictive value of ${ }^{18} \mathrm{~F}$-FDG PET/CT-based response assessment, relapses remain problematic. Therefore, other disease characteristics such as bulky tumors $(>5 \mathrm{~cm})$, high stage $(>\mathrm{IIB})$, or pelvic or paraaortic lymph node metastasis can be used to direct more aggressive treatment or adjuvant chemotherapy regimens (97). In cervical cancer, apart from being used for posttherapeutic response assessment, ${ }^{18}$ F-FDG PET/CT has been investigated for monitoring of response during radiotherapy. Despite some promising results, future clinical trials are warranted (98).

Although some limitations of ${ }^{18}$ F-FDG PET/CT-based therapy response assessment in radiation oncology can be overcome by careful design and implementation of imaging protocols, the inherent limitation caused by radiation-induced inflammation makes interpretation of treatment-response results difficult. To overcome this limitation, the focus of PET imaging is shifting to more tumor-specific characteristics (e.g., cellular proliferation, hypoxia, angiogenesis, and apoptosis). Currently, the most established of these is imaging of cellular proliferation using ${ }^{18} \mathrm{~F}$-FLT PET, a surrogate of cellular proliferation. The characteristics of ${ }^{18}$ F-FLT make it suitable for static PET imaging, with a reasonable uptake period and dynamic PET imaging that can be subsequently analyzed for kinetics $(99,100)$. The potential of ${ }^{18} \mathrm{~F}$-FLT PET/CT for early assessment of chemotherapy has been demonstrated in a variety of cancers (101-103). In the context of radiotherapy, ${ }^{18} \mathrm{~F}-\mathrm{FLT}$ PET/CT first proved its sensitivity to ionizing radiation in preclinical tumor models $(104,105)$. After promising results from ${ }^{18} \mathrm{~F}$-FLT PET/CT-based assessments of radiation response in these models, an increasing number of studies have shown that decreased ${ }^{18}$ F-FLT uptake early (as early as $5 \mathrm{~d} /$ $10 \mathrm{~Gy}$ ) in the course of radiotherapy or chemoradiotherapy is a strong indicator of long-term outcome in a large-animal preclinical model (106) and humans (107-110) (Fig. 2). Although the data on ${ }^{18} \mathrm{~F}-\mathrm{FLT}$ PET/CT response assessment in radiation therapy are still emerging, its potential is indisputable, and it should be considered an alternative to ${ }^{18} \mathrm{~F}$-FDG PET/CT. One alternative PET surrogate marker of cellular proliferation is ${ }^{11} \mathrm{C}$ - and ${ }^{18} \mathrm{~F}$-choline, which appears relatively sensitive for detecting recurring prostate cancer (111). Another is L-[methyl- $\left.{ }^{11} \mathrm{C}\right]$-methionine, which may be useful for late response evaluation in brain cancer (112).

Apart from cellular proliferation imaging, hypoxia is another tumor-specific characteristic that has been successfully imaged and used for radiotherapy response assessment in clinical studies. Although tumor hypoxia is widely recognized as a negative prognostic factor in radiation oncology, hypoxic tumor subvolumes often change during radiotherapy $(113,114)$. Treatment outcome may correlate more with hypoxia assessed during radiotherapy than before radiotherapy (115) (Fig. 2 (116)).

Similar to PET-based radiotherapy response assessment, SPECT

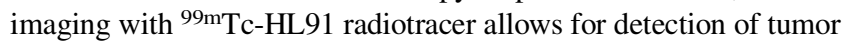
hypoxia and has significant predictive power for tumor response and patient survival (117). SPECT imaging with the ${ }^{99 \mathrm{~m} T c-h y d r a z i n o-}$ nicotinamide-rh-annexin $\mathrm{V}$ radiotracer also allows for evaluating apoptosis in tumors. Apoptotic SPECT imaging has shown radiation dose-dependent uptake in the parotid glands within $2 \mathrm{~d}$ after the first course of chemoradiotherapy (6-8 Gy) in head and neck cancer patients; such uptake was indicative of early apoptosis during radiotherapy (118).

In addition to nuclear medicine molecular imaging techniques, MR-based molecular imaging has long been investigated for early radiotherapy response assessment. Research has focused primarily on DCE and DW MRI. For example, increased perfusion early during the course of radiotherapy (within the first 2 wk) assessed with DCE MRI has been shown to be a strong predictor of tumor regression and local control in cervical cancer treated with conventional radiotherapy (119). Also, pretherapy DCE MRI perfusion, permeability, or blood volume measurements have been associated with radiation treatment response in rectal cancers (120) and brain cancers (121). Water diffusion in the tissue can be assessed with DW MRI through the ADCs. Low ADCs measured before radiotherapy have been shown to be associated with response to radiotherapy for brain lesions (122), cervical cancer (123), and head and neck cancer (124). Similarly, increases in ADCs measured during radiotherapy in patients with brain (122), cervical (123), liver (125), rectal (126), and head and neck cancer (124) have been shown to be associated with a favorable outcome. Obstacles toward more successful use of DCE or DW MRI for treatment response assessment includes the unknown optimal timing of DCE MRI (which is most likely disease-dependent (127)), and the lack of reproducibility in ADCs between vendors and institutions (128).

\section{Spatially Resolved Treatment Response Evaluation}

Solid cancers have intrinsic spatial heterogeneity in biologic characteristics, which limits the efficacy of point measurements such as biopsy-based molecular assays or point measures derived from PET images (e.g., $\mathrm{SUV}_{\max }$ ). Methods to incorporate spatial heterogeneities 
into treatment response assessment are an active area of research. An obvious approach to incorporate the intratumoral heterogeneity into treatment response would be to evaluate spatial therapeutic response. Therapeutic response can be evaluated at a voxel level as absolute change in the PET values $(129,130)$ or as relative change from the baseline image (131). Evaluation of relative changes on a voxel level is unreliable for tumor subvolumes with a very low baseline PET value, for which relative changes may be high despite both baseline and posttherapy PET image values within the background range. Evaluation of absolute change in PET values on a voxel level $(129,130)$ might be less sensitive to cases of very low baseline PET values. An evaluation of the therapeutic response on a voxel level is also strongly affected by the selection of registration algorithm (131).

Intratumoral heterogeneity can also be incorporated into treatment response assessment by the extraction of various textural features from molecular images (popularly termed radiomics). These features are subsequently used for therapy response assessment instead of or in addition to point SUV measures (i.e., $\mathrm{SUV}_{\text {peak }}$ and $S_{U V} V_{\text {max }}$ ) or overall SUV measures (i.e., $S_{U V}$ mean and $S_{U V}$ total). Although the use of texture analysis in molecular imaging is still in its infancy, some successful applications in radiation oncology have already been published. Various textural features that were extracted from pretreatment ${ }^{18} \mathrm{~F}$-FDG PET images have been correlated to treatment outcome in breast, cervix, esophageal, head and neck, and lung cancer tumors (132). Changes in textural features of ${ }^{18}$ F-FDG PET images during and after chemoradiotherapy have also been significantly correlated to time to progression and survival in rectal cancer patients (133).

A common technical limitation of all approaches for incorporating intratumoral heterogeneity into treatment response assessment is the influence of image acquisition and reconstruction parameters on image heterogeneity measures. Image acquisition and reconstruction intrinsically implement some smoothing and possibly other distortions of the data, in comparison to the real data, the degree of which depends on the imaging hardware and software, and also on the acquisition and reconstruction settings. Therefore, sequential imaging for voxel-based treatment response assessment and for extraction of imaging features would have to be performed on the same scanner with the same acquisition and reconstruction settings. Alternatively, different scanners could produce comparable results if they were carefully harmonized. However, interchangeability of textural features from different but carefully harmonized PET/CT scanners has yet to be proved.

\section{Adaptation}

The main goal of early molecular-imaging response assessment during radiation therapy is to allow therapy to be modified to improve the clinical outcome-the so-called biologically adaptive radiotherapy. The radiation is adapted during therapy to match corresponding changes in tumor physiology as derived from molecular imaging. Modeling studies have demonstrated potential for significant improvement of clinical outcome using biologically adaptive radiotherapy (134), whereas the clinical evidence has yet to be provided.

Although ${ }^{18} \mathrm{~F}$-FDG PET/CT is the molecular imaging technique with the highest clinical acceptance and availability $(68,135)$, treatment adaption based on ${ }^{18} \mathrm{~F}$-FDG PET/CT is hampered by the inflammatory signal after radiotherapy. The potential use of ${ }^{18}$ F-FDG PET/CT for adaptive tumor dose escalation or normaltissue sparing has been investigated in patients with NSCLC (135) and even coupled with dose painting in patients with head and neck cancer (68). Both studies found significant changes in target

TABLE 3

Selected References on Early Response Assessment and Treatment Adaption, Late Response Assessment, and Normal-Tissue Response Evaluation

\begin{tabular}{|c|c|c|c|}
\hline Cancer type & $\begin{array}{c}\text { Early response assessment } \\
\text { and treatment }\end{array}$ & $\begin{array}{l}\text { Late response } \\
\text { assessment }\end{array}$ & $\begin{array}{c}\text { Normal-tissue response } \\
\text { evaluation }\end{array}$ \\
\hline \multirow[t]{3}{*}{ Lung } & ${ }^{18}$ F-FDG PET $(82-85,135)$ & ${ }^{18}$ F-FDG PET (81) & ${ }^{18} \mathrm{~F}-\mathrm{FDG}$ PET $(136,139-141)$ \\
\hline & Non- ${ }^{18}$ F-FDG PET $(107,110)$ & & SPECT $(75,136-138)$ \\
\hline & & & MRI $(136,138)$ \\
\hline \multirow{4}{*}{$\begin{array}{l}\text { Head and } \\
\text { neck }\end{array}$} & ${ }^{18}$ F-FDG PET $(68,90)$ & ${ }^{18}$ F-FDG PET (87-89) & ${ }^{18} \mathrm{~F}-\mathrm{FDG}$ PET (142) \\
\hline & Non- ${ }^{18}$ F-FDG PET $(108,109)$ & & Non- ${ }^{18}$ F-FDG PET (138) \\
\hline & SPECT (118) & & SPECT (138) \\
\hline & MRI (124) & & MRI (138) \\
\hline \multirow[t]{2}{*}{ Rectal } & ${ }^{18}$ F-FDG PET $(91,92)$ & ${ }^{18} \mathrm{~F}-\mathrm{FDG}$ PET (93) & \\
\hline & MRI (126) & & \\
\hline Esophageal & ${ }^{18}$ F-FDG PET (95) & ${ }^{18} \mathrm{~F}-F D G$ PET (94) & ${ }^{18} \mathrm{~F}-\mathrm{FDG}$ PET (143) \\
\hline \multirow[t]{2}{*}{ Cervical } & ${ }^{18} \mathrm{~F}-\mathrm{FDG}$ PET (98) & ${ }^{18} \mathrm{~F}-\mathrm{FDG}$ PET (96) & ${ }^{18} \mathrm{~F}-\mathrm{FDG}$ PET (144) \\
\hline & MRI $(119,123)$ & & Non-18F-FDG PET (145) \\
\hline \multirow[t]{3}{*}{ Brain } & MRI (122) & Non- ${ }^{18}$ F-FDG PET (112) & ${ }^{18} \mathrm{~F}-\mathrm{FDG}$ PET $(136,146,147)$ \\
\hline & & & Non- ${ }^{18} \mathrm{~F}-\mathrm{FDG}$ PET $(146,148)$ \\
\hline & & & MRI $(136,147)$ \\
\hline \multirow[t]{3}{*}{ Liver } & MRI (125) & & Non-18F-FDG PET (138) \\
\hline & & & SPECT (138) \\
\hline & & & MRI (138) \\
\hline
\end{tabular}


TABLE 4

NCCN Recommendations on Use of ${ }^{18}$ F-FDG PET/CT for Target Definition and Treatment Response Evaluation in Radiotherapy

\begin{tabular}{|c|c|c|}
\hline $\begin{array}{c}\text { Cancer } \\
\text { type }\end{array}$ & $\begin{array}{c}\text { Target } \\
\text { definition }\end{array}$ & $\begin{array}{l}\text { Response } \\
\text { evaluation }\end{array}$ \\
\hline Cervical & Recommended & Optional \\
\hline Esophageal & Recommended & Recommended \\
\hline Head and neck & - & Optional \\
\hline $\begin{array}{l}\text { Hodgkin } \\
\text { lymphoma }\end{array}$ & Optional & Recommended \\
\hline $\begin{array}{l}\text { Non-Hodgkin } \\
\text { lymphoma }\end{array}$ & Optional & Recommended \\
\hline $\begin{array}{r}\text { Non-small } \\
\text { cell lung }\end{array}$ & Recommended & - \\
\hline $\begin{array}{l}\text { Small } \\
\text { cell lung }\end{array}$ & Recommended & - \\
\hline Pancreatic & Recommended & - \\
\hline
\end{tabular}

Recommendations are as of 2015. No significant evidence to support use of ${ }^{18} \mathrm{~F}-\mathrm{FDG}$ PET/CT at this point is indicated with a dash, which does not mean that use of ${ }^{18} \mathrm{~F}-\mathrm{FDG}$ PET/CT may not be beneficial but merely that evidence at this point is still insufficient.

volumes based on mid-therapy ${ }^{18} \mathrm{~F}-\mathrm{FDG}$ PET/CT images, warranting replanning of the treatment target.

In addition to ${ }^{18} \mathrm{~F}$-FDG PET, more specific (e.g., cellular proliferation, hypoxia) imaging biomarkers can be used for radiotherapy adaption. As a rapid decrease in ${ }^{18}$ F-FLT uptake has been demonstrated as early as $5 \mathrm{~d} / 10 \mathrm{~Gy}$ in the course of radiotherapy (107-110), early radiotherapy adaption based on ${ }^{18} \mathrm{~F}$-FLT PET/CT imaging appears particularly attractive. The clinical utility of early radiotherapy adaption based on ${ }^{18} \mathrm{~F}-\mathrm{FLT}$ PET/CT has yet to be demonstrated.

\section{Normal-Tissue Response Evaluation}

The main application of molecular imaging for normal-tissue response evaluation is the detection of radiation-induced injuries to these tissues. Monitoring induction, resolution, and mitigation of radiation-induced toxicity is essential in the development of clinically successful strategies to preserve normal tissues. Molecular imaging can be particularly useful to study and monitor these changes.

Lung Cancer. In lung cancer, normal-tissue response assessment has focused mainly on detection of radiation-induced lung toxicity and inflammation. The mainstay of imaging for detection of radiationinduced lung toxicity remains SPECT perfusion and ventilation for evaluating pulmonary function $(75,136-138) .{ }^{18} \mathrm{~F}-\mathrm{FDG}$ PET and DCE MRI have also been investigated for imaging radiation-induced lung toxicity $(137,138)$. The functional relationship between posttherapy ${ }^{18} \mathrm{~F}-\mathrm{FDG}$ uptake and radiation dose has been measured and shown to correlate with the clinical symptoms of radiation pneumonitis after thoracic radiotherapy (139). The intensity of posttherapy ${ }^{18} \mathrm{~F}-\mathrm{FDG}$ uptake was related to the severity of radiation pneumonitis using a simple visual scoring system (140). Similarly, increased ${ }^{18}$ F-FDG uptake in normal lung was associated with the subsequent development of clinical radiation-induced lung toxicity early during radiotherapy (141).
Head and Neck Cancer. In head and neck cancer, xerostomia is the most common major normal-tissue complication after radiation therapy. Decreased parotid uptake of ${ }^{18} \mathrm{~F}-\mathrm{FDG}$ on postradiotherapy $\mathrm{PET} / \mathrm{CT}$ images has been associated with early parotid toxicity as defined by posttreatment salivary output and xerostomia scores. Interestingly, pretreatment ${ }^{18} \mathrm{~F}$-FDG PET/CT in conjunction with the radiation dose distribution can predict changes in parotid ${ }^{18} \mathrm{~F}-\mathrm{FDG}$ uptake, which can potentially be exploited to guide function-sparing treatment planning (142). Besides being studied with ${ }^{18} \mathrm{~F}-\mathrm{FDG}$ PET, salivary gland function has been studied with L-[methyl- $\left.{ }^{11} \mathrm{C}\right]-$ methionine PET, ${ }^{99 \mathrm{~m} T c-p e r t e c h n e t a t e ~ S P E C T, ~ a n d ~ f u n c t i o n a l ~ M R I ~(138) . ~}$

Esophageal Cancer. In esophageal cancer, research has focused primarily on assessing the myocardium for radiation-induced damage. Focally increased ${ }^{18}$ F-FDG uptake in the basal myocardium after radiotherapy has been hypothesized to be related to radiation-induced myocardial damage. Therefore, cardiac function and other symptoms should be followed carefully in patients with elevated ${ }^{18} \mathrm{~F}-\mathrm{FDG}$ uptake in the myocardium (143).

Cervical Cancer. In cervical cancer, pelvic bone marrow irradiation during radiotherapy causes hematologic toxicity, which can be more severe in the case of concomitant chemotherapy. Generally, bone marrow activity can be measured by several imaging modalities, such as CT, MRI, and PET. Imaging with ${ }^{18} \mathrm{~F}$-FDG PET or ${ }^{18} \mathrm{~F}-\mathrm{FLT}$ PET has been shown to help differentiate active from nonactive bone marrow in cervical cancer patients who have undergone chemoradiotherapy $(144,145)$.

Brain Tumors. In brain tumors, distinguishing tumor growth from radiation-induced injury is often challenging, as both are often visible on posttherapy molecular images. ${ }^{18} \mathrm{~F}-\mathrm{FDG}$ and ${ }^{18}$ F-FLT PET imaging have shown promise in the differentiation of recurrent glioma from radiation necrosis through both quantitative and visual image assessment (146). Similarly, ${ }^{18} \mathrm{~F}-\mathrm{FDG}$ PET/CT and dynamic susceptibility-weighted contrast-enhanced perfusion MRI have demonstrated the ability to differentiate tumor growth from radiation injury (147). ${ }^{18} \mathrm{~F}$-DOPA PET has also been shown to effectively differentiate recurrent or progressive brain metastases from late or delayed radiation injury (148). In addition, radiation-induced brain injury can be assessed with various other MRI techniques (136).

Liver Cancer. In liver cancer, the liver is the most important organ at risk; information on the spatial distribution of liver function is therefore highly valuable for assessing radiationinduced liver toxicity. DCE CT is the current mainstay of liver function spatial assessment; MRI and PET/CT have been studied but to only a limited extent (138).

Several specific challenges in molecular imaging of normal-tissue effects remain. For example, radiation therapy is often combined with chemotherapy and molecularly targeted therapies, with normaltissue toxicity resulting either from each modality separately or through a synergistic effect of combined therapies. Furthermore, potential inhibition of the inflammatory effects with antiinflammatory compounds (e.g., inhibitors of nuclear factor $\kappa \mathrm{B}$ and interleukin-1 signaling) may significantly affect management of radiation-induced toxicity. Much work still needs to be done in the development of relevant molecular imaging agents to effectively probe these processes and fully explore the potential that molecular imaging offers.

\section{IMPEDIMENTS TO BROADER USE}

Overall, molecular imaging has many potential uses in assessing response to radiation therapy and in evaluating radiation-induced 
injury. Various initiatives to use molecular imaging for early response assessment, treatment adaption, late response assessment, and normal-tissue response evaluation in radiation oncology are outlined in Table 3. In the context of the increasing trend toward personalization of therapies, it is likely that some of the methods presented here as research initiatives will soon become clinical practice.

Molecular imaging is already strongly embedded in radiotherapy; however, the path to widespread and inclusive use in all steps of the radiation treatment process, particularly in planning and evaluation, is still long. In addition to the lack of insurance coverage for scans, the lack of solid clinical evidence is a major impediment to broader use. Recommendations for practicing physicians are still scarce. Of particular note are the National Comprehensive Cancer Network (NCCN) evidence-based guidelines for treating various cancers (www.nccn.org). The NCCN guidelines specific to the use of ${ }^{18} \mathrm{~F}$-FDG PET/CT imaging have recently been summarized by the PET Use Task Force of the Society of Nuclear Medicine and Molecular Imaging and can be found on its website (http://snmmi.files. cms-plus.com/FileDownloads/Centers/NCCNPracticeGuidelinesII. pdf). Table 4 summarizes the NCCN recommendations for PET/CT applications specific to radiation therapy, not including PET/CT applications in diagnosis and staging. As the clinical evidence from multiple clinical trials and clinical practice becomes available for different disease sites and applications, one can expect that this list will grow rapidly. Similar guidelines, some of which are more specific to a particular treatment process or procedures (e.g., use of ${ }^{18} \mathrm{~F}$-FDG PET/CT for tumor delineation) are emerging from the key professional organizations, such as the Society of Nuclear Medicine and Molecular Imaging, European Association of Nuclear Medicine, AAPM, American Association of Therapeutic Radiation Oncology, European Society for Therapeutic Radiation Oncology, and International Committee for Radiation Units.

\section{CONCLUSION}

Clearly, the use of molecular imaging in radiation oncology is continuing to grow. With increasing presence, special emphasis should be put on adequate training of radiation oncology personnel to understand the potential, and particularly the limitations, of quantitative molecular imaging applications. Furthermore, strong collaboration between radiation oncology, nuclear medicine/radiology, and medical physics teams is necessary, as optimal and safe use of molecular imaging can be ensured only within appropriate interdisciplinary teams.

\section{REFERENCES}

1. Delbeke D, Coleman RE, Guiberteau MJ, et al. Procedure guideline for tumor imaging with ${ }^{18}$ F-FDG PET/CT 1.0. J Nucl Med. 2006;47:885-895.

2. Boellaard R, O'Doherty MJ, Weber WA, et al. FDG PET and PET/CT: EANM procedure guidelines for tumour PET imaging-version 1.0. Eur J Nucl Med Mol Imaging. 2010;37:181-200.

3. Vander Borght T, Asenbaum S, Bartenstein P, et al. EANM procedure guidelines for brain tumour imaging using labelled amino acid analogues. Eur J Nucl Med Mol Imaging. 2006;33:1374-1380.

4. Segall G, Delbeke D, Stabin MG, et al. SNM practice guideline for sodium ${ }^{18}$ F-fluoride PET/CT bone scans 1.0. J Nucl Med. 2010;51:1813-1820.

5. ACR practice parameters and technical standards. American College of Radiology website. http://www.acr.org/Quality-Safety/Standards-Guidelines. Accessed September 10, 2015

6. Mutic S, Palta JR, Butker EK, et al. Quality assurance for computed-tomography simulators and the computed-tomography-simulation process: report of the AAPM Radiation Therapy Committee Task Group No. 66. Med Phys. 2003;30:2762-2792.
7. Mantlik F, Hofmann M, Werner MK, et al. The effect of patient positioning aids on PET quantification in PET/MR imaging. Eur J Nucl Med Mol Imaging. 2011;38:920-929.

8. van der Heide UA, Houweling AC, Groenendaal G, Beets-Tan RG, Lambin P. Functional MRI for radiotherapy dose painting. Magn Reson Imaging. 2012;30: 1216-1223.

9. Verduijn GM, Bartels LW, Raaijmakers CP, Terhaard CH, Pameijer FA, van den Berg CA. Magnetic resonance imaging protocol optimization for delineation of gross tumor volume in hypopharyngeal and laryngeal tumors. Int J Radiat Oncol Biol Phys. 2009;74:630-636.

10. Mawlawi O, Erasmus JJ, Munden RF, et al. Quantifying the effect of IV contrast media on integrated PET/CT: clinical evaluation. AJR. 2006;186:308-319.

11. Hofmann M, Steinke F, Scheel V, et al. MRI-based attenuation correction for PET/MRI: a novel approach combining pattern recognition and atlas registration. J Nucl Med. 2008;49:1875-1883.

12. Paulus DH, Thorwath D, Schmidt H, Quick HH. Towards integration of PET/ MR hybrid imaging into radiation therapy treatment planning. Med Phys. 2014;41:072505.

13. Yip S, Chen AB, Aerts HJ, Berbeco R. Sensitivity study of voxel-based PET image comparison to image registration algorithms. Med Phys. 2014;41:111714.

14. Mutic S, Dempsey JF, Bosch WR, et al. Multimodality image registration quality assurance for conformal three-dimensional treatment planning. Int $J$ Radiat Oncol Biol Phys. 2001;51:255-260.

15. Lupi A, Zaroccolo M, Salgarello M, Malfatti V, Zanco P. The effect of ${ }^{18} \mathrm{~F}$-FDG-PET/CT respiratory gating on detected metabolic activity in lung lesions. Ann Nucl Med. 2009;23:191-196.

16. Keall PJ, Mageras GS, Balter JM, et al. The management of respiratory motion in radiation oncology report of AAPM Task Group 76. Med Phys. 2006;33: 3874-3900.

17. Lagerwaard FJ, Van Sornsen de Koste JR, Nijssen-Visser MR, et al. Multiple "slow" CT scans for incorporating lung tumor mobility in radiotherapy planning. Int J Radiat Oncol Biol Phys. 2001;51:932-937.

18. Bowen SR, Nyflot MJ, Gensheimer M, et al. Challenges and opportunities in patient-specific, motion-managed and PET/CT-guided radiation therapy of lung cancer: review and perspective. Clin Transl Med. 2012;1:18.

19. Keall PJ, Kini VR, Vedam SS, Mohan R. Motion adaptive x-ray therapy: a feasibility study. Phys Med Biol. 2001;46:1-10.

20. Schweikard A, Glosser G, Bodduluri M, Murphy MJ, Adler JR. Robotic motion compensation for respiratory movement during radiosurgery. Comput Aided Surg. 2000;5:263-277.

21. Boellaard R. Standards for PET image acquisition and quantitative data analysis. J Nucl Med. 2009;50(suppl 1):11S-20S.

22. Jeraj R, Bowen S, Deveau M, Galavis P, Jallow N. Biologically conformal radiotherapy: targeting based on biological imaging. In: Palta J, Mackie R, eds. Uncertainties in External Beam Radiation Therapy. 2011, Madison, WI: Medical Physics Publishing; 2011.

23. Kumar R, Chauhan A, Zhuang H, Chandra P, Schnall M, Alavi A. Clinicopathologic factors associated with false negative FDG-PET in primary breast cancer. Breast Cancer Res Treat. 2006;98:267-274.

24. Carey JE, Byrne P, DeWerd L, Lieto R, Petry N. The Selection, Use, Calibration, and Quality Assurance of Radionuclide Calibrators Used in Nuclear Medicine. College Park, MD: American Association of Physicists in Medicine; 2012. AAPM report 181.

25. Busemann Sokole E, Płachcínska A, Britten A, Lyra Georgosopoulou M, Tindale W, Klett R. Routine quality control recommendations for nuclear medicine instrumentation. Eur J Nucl Med Mol Imaging. 2010;37:662-671.

26. Velasquez LM, Boellaard R, Kollia G, et al. Repeatability of ${ }^{18}$ F-FDG PET in a multicenter phase I study of patients with advanced gastrointestinal malignancies. J Nucl Med. 2009;50:1646-1654.

27. Minn H, Zasadny KR, Quint LE, Wahl RL. Lung cancer: reproducibility of quantitative measurements for evaluating 2-[F-18]-fluoro-2-deoxy-D-glucose uptake at PET. Radiology. 1995;196:167-173.

28. McCall KC, Barbee DL, Kissick MW, Jeraj R. PET imaging for the quantification of biologically heterogeneous tumours: measuring the effect of relative position on image-based quantification of dose-painting targets. Phys Med Biol. 2010;55:2789-2806.

29. Padhani AR, Liu G, Koh DM, et al. Diffusion-weighted magnetic resonance imaging as a cancer biomarker: consensus and recommendations. Neoplasia. 2009;11:102-125.

30. Raunig DL, McShane LM, Pennello G, et al. Quantitative imaging biomarkers: a review of statistical methods for technical performance assessment. Stat Methods Med Res. 2015;24:27-67.

31. Jaskowiak CJ, Bianco JA, Perlman SB, Fine JP. Influence of reconstruction iterations on ${ }^{18}$ F-FDG PET/CT standardized uptake values. J Nucl Med.2005;46:424-428. 
32. Boellaard R, Oyen WJ, Hoekstra CJ, et al. The Netherlands protocol for standardisation and quantification of FDG whole body PET studies in multi-centre trials. Eur J Nucl Med Mol Imaging. 2008;35:2320-2333.

33. Graham MM, Wahl RL, Hoffman JM, et al. Summary of the UPICT protocol for ${ }^{18} \mathrm{~F}-\mathrm{FDG}$ PET/CT imaging in oncology clinical trials. J Nucl Med. 2015;56:955-961.

34. Boellaard R. Need for standardization of ${ }^{18} \mathrm{~F}-\mathrm{FDG}$ PET/CT for treatment response assessments. J Nucl Med. 2011;52(suppl 2):93S-100S.

35. Van de Steene J, Linthout N, de Mey J, et al. Definition of gross tumor volume in lung cancer: inter-observer variability. Radiother Oncol. 2002;62:37-49.

36. Kubota R, Yamada S, Kubota K, Ishiwata K, Tamahashi N, Ido T. Intratumoral distribution of fluorine-18-fluorodeoxyglucose in vivo: high accumulation in macrophages and granulation tissues studied by microautoradiography. $\mathrm{J} \mathrm{Nucl}$ Med. 1992;33:1972-1980.

37. Caldwell CB, Stein NF, Riegel AC, et al. Observer variation in contouring gross tumor volume in patients with poorly defined non-small-cell lung tumors on CT: the impact of ${ }^{18}$ FDG-hybrid PET fusion. Int J Radiat Oncol Biol Phys. 2001;51:923-931

38. Berson AM, Stein NF, Riegel AC, et al. Variability of gross tumor volume delineation in head-and-neck cancer using PET/CT fusion, part II: the impact of a contouring protocol. Med Dosim. 2009;34:30-35.

39. Schakel T, Hoogduin JM, Terhaard CH, Philippens ME. Diffusion weighted MRI in head-and-neck cancer: geometrical accuracy. Radiother Oncol. 2013;109: 394-397.

40. Wang D, Schultz CJ, Jursinic PA, et al. Initial experience of FDG-PET/CT guided IMRT of head-and-neck carcinoma. Int J Radiat Oncol Biol Phys. 2006;65:143-151

41. Ciernik IF, Dizendorf E, Baumert BG, et al. Radiation treatment planning with an integrated positron emission and computer tomography (PET/CT): a feasibility study. Int J Radiat Oncol Biol Phys. 2003;57:853-863.

42. King MA, Long DT, Brill AB. SPECT volume quantitation: influence of spatial resolution, source size and shape, and voxel size. Med Phys. 1991;18:10161024.

43. Xing L, Siebers J, Keall P. Computational challenges for image-guided radiation therapy: framework and current research. Semin Radiat Oncol. 2007;17: 245-257.

44. Shepherd T, Teras M, Beichel RR, et al. Comparative study with new accuracy metrics for target volume contouring in PET image guided radiation therapy. IEEE Trans Med Imaging. 2012;31:2006-2024.

45. Warfield SK, Zou KH, Wells WM. Simultaneous truth and performance level estimation (STAPLE): an algorithm for the validation of image segmentation. IEEE Trans Med Imaging. 2004;23:903-921.

46. Heiss P, Mayer S, Herz M, Wester HJ, Schwaiger M, SenekowitschSchmidtke R. Investigation of transport mechanism and uptake kinetics of O-(2-[ ${ }^{18}$ F]fluoroethyl)-L-tyrosine in vitro and in vivo. J Nucl Med. 1999;40:13671373.

47. Pirotte B, Goldman S, Massager N, et al. Comparison of ${ }^{18} \mathrm{~F}-\mathrm{FDG}$ and ${ }^{11} \mathrm{C}$ methionine for PET-guided stereotactic brain biopsy of gliomas. J Nucl Med. 2004;45:1293-1298.

48. Becherer A, Karanikas G, Szabó M, et al. Brain tumour imaging with PET: a comparison between $\left[{ }^{18} \mathrm{~F}\right]$ fluorodopa and $\left[{ }^{11} \mathrm{C}\right]$ methionine. Eur J Nucl Med Mol Imaging. 2003;30:1561-1567.

49. Schöder H, Carlson DL, Kraus DH, et al. ${ }^{18}$ F-FDG PET/CT for detecting nodal metastases in patients with oral cancer staged N0 by clinical examination and CT/MRI. J Nucl Med. 2006;47:755-762.

50. Grosu AL, Weber WA. PET for radiation treatment planning of brain tumours. Radiother Oncol. 2010;96:325-327.

51. Troost EG, Schinagl DA, Bussink J, Oyen WJ, Kaanders JH. Clinical evidence on PET-CT for radiation therapy planning in head and neck tumours. Radiother Oncol. 2010;96: 328-334.

52. De Ruysscher D, Kirsch C-M. PET scans in radiotherapy planning of lung cancer. Radiother Oncol. 2010;96:335-338.

53. Lambrecht M, Haustermans K. Clinical evidence on PET-CT for radiation therapy planning in gastro-intestinal tumors. Radiother Oncol. 2010. 96:339346.

54. Picchio M, Giovannini E, Crivellaro C, Gianolli L, di Muzio N, Messa C. Clinical evidence on PET/CT for radiation therapy planning in prostate cancer. Radiother Oncol. 2010;96:347-350.

55. Haie-Meder C, Mazeron R, Magne N. Clinical evidence on PET-CT for radiation therapy planning in cervix and endometrial cancers. Radiother Oncol. 2010;96:351-355

56. Lu YY, Chen JH, Ding HJ, Chien CR, Lin WY, Kao CH. A systematic review and meta-analysis of pretherapeutic lymph node staging of colorectal cancer by ${ }^{18}$ F-FDG PET or PET/CT. Nucl Med Commun. 2012;33:1127-1133.
57. Ling CC, Humm J, Larson S, et al. Towards multidimensional radiotherapy (MD-CRT): biological imaging and biological conformality. Int J Radiat Oncol Biol Phys. 2000;47:551-560.

58. Raktoe SA, Dehnad H, Raaijmakers CP, Braunius W, Terhaard CH. Origin of tumor recurrence after intensity modulated radiation therapy for oropharyngeal squamous cell carcinoma. Int J Radiat Oncol Biol Phys. 2013;85:136-141.

59. Gerlinger M, Rowan AJ, Horswell S, et al. Intratumor heterogeneity and branched evolution revealed by multiregion sequencing. N Engl J Med. 2012;366:883-892.

60. Mortensen LS, Johansen J, Kallehauge J, et al. FAZA PET/CT hypoxia imaging in patients with squamous cell carcinoma of the head and neck treated with radiotherapy: results from the DAHANCA 24 trial. Radiother Oncol. 2012;105: 14-20.

61. Bradshaw TJ, Bowen SR, Deveau MA, et al. Molecular imaging biomarkers of resistance to radiation therapy for spontaneous nasal tumors in canines. Int $J$ Radiat Oncol Biol Phys. 2015;91:787-795.

62. Bowen SR, Chappell RJ, Bentzen SM, Deveau MA, Forrest LJ, Jeraj R. Spatially resolved regression analysis of pre-treatment FDG, FLT and Cu-ATSM PET from post-treatment FDG PET: an exploratory study. Radiother Oncol. 2012;105:41-48

63. Bentzen SM. Theragnostic imaging for radiation oncology: dose-painting by numbers. Lancet Oncol. 2005;6:112-117.

64. Deveau MA, Bowen SR, Westerly DC, Jeraj R. Feasibility and sensitivity study of helical tomotherapy for dose painting plans. Acta Oncol. 2010;49:991-996.

65. Douglas JG, Stelzer KJ, Mankoff DA. [F-18]-fluorodeoxyglucose positron emission tomography for targeting radiation dose escalation for patients with glioblastoma multiforme: clinical outcomes and patterns of failure. Int J Radiat Oncol Biol Phys. 2006;64:886-891.

66. Piroth MD, et al. Integrated boost IMRT with FET-PET-adapted local dose escalation in glioblastomas: results of a prospective phase II study. Strahlenther Onkol. 2012;188:334-339.

67. Berwouts D, Olteanu LA, Duprez F, et al. Three-phase adaptive dose-paintingby-numbers for head-and-neck cancer: initial results of the phase I clinical trial. Radiother Oncol. 2013;107:310-316.

68. Duprez F, De Neve W, De Gersem W, Coghe M, Madani I. Adaptive dose painting by numbers for head-and-neck cancer. Int J Radiat Oncol Biol Phys. 2011;80:1045-1055.

69. Madani I, Duthoy W, Derie C, et al. Positron emission tomography-guided, focal-dose escalation using intensity-modulated radiotherapy for head and neck cancer. Int J Radiat Oncol Biol Phys. 2007;68:126-135.

70. Pinkawa M, Piroth MD, Holy R, et al. Dose-escalation using intensity-modulated radiotherapy for prostate cancer: evaluation of quality of life with and without ${ }^{18} \mathrm{~F}$-choline PET-CT detected simultaneous integrated boost. Radiat Oncol. 2012;7:14.

71. van Elmpt W, De Ruysscher D, van der Salm A, et al. The PET-boost randomised phase II dose-escalation trial in non-small cell lung cancer. Radiother Oncol. 2012;104:67-71.

72. Petit SF, van Elmpt WJ, Oberije CJ, et al. $\left[{ }^{8} \mathrm{~F}\right]$ fluorodeoxyglucose uptake patterns in lung before radiotherapy identify areas more susceptible to radiationinduced lung toxicity in non-small-cell lung cancer patients. Int J Radiat Oncol Biol Phys. 2011;81:698-705.

73. Eichinger M, Tetzlaff R, Puderbach M, Woodhouse N, Kauczor HU. Proton magnetic resonance imaging for assessment of lung function and respiratory dynamics. Eur J Radiol. 2007;64:329-334.

74. Simon BA. Non-invasive imaging of regional lung function using x-ray computed tomography. J Clin Monit Comput. 2000;16:433-442.

75. Marks LB, Spencer DP, Bentel GC, et al. The utility of SPECT lung perfusion scans in minimizing and assessing the physiologic consequences of thoracic irradiation. Int J Radiat Oncol Biol Phys. 1993;26:659-668.

76. Ireland RH, Bragg CM, McJury M, et al. Feasibility of image registration and intensity-modulated radiotherapy planning with hyperpolarized helium-3 magnetic resonance imaging for non-small-cell lung cancer. Int J Radiat Oncol Biol Phys. 2007;68:273-281.

77. Vansteenkiste JF, Stroobants SG, Dupont PJ, et al. Prognostic importance of the standardized uptake value on ${ }^{18} \mathrm{~F}$-fluoro-2-deoxy-glucose-positron emission tomography scan in non-small-cell lung cancer: an analysis of 125 cases. Leuven Lung Cancer Group. J Clin Oncol. 1999;17:3201-3206.

78. Young H, Baum R, Cremerius U, et al. Measurement of clinical and subclinical tumour response using $\left[{ }^{18} \mathrm{~F}\right]$-fluorodeoxyglucose and positron emission tomography: review and 1999 EORTC recommendations. European Organization for Research and Treatment of Cancer (EORTC) PET Study Group. Eur J Cancer. 1999;35:1773-1782.

79. Shankar LK, Hoffman JM, Bacharach S, et al. Consensus recommendations for the use of ${ }^{18} \mathrm{~F}$-FDG PET as an indicator of therapeutic response in patients in National Cancer Institute Trials. J Nucl Med. 2006;47:1059-1066. 
80. Wahl RL, Jacene H, Kasamon Y, Lodge MA. From RECIST to PERCIST: evolving considerations for PET response criteria in solid tumors. $\mathrm{J} \mathrm{Nucl}$ Med. 2009;50(suppl 1):122S-150S.

81. van Baardwijk A, Dooms C, van Suylen RJ, et al. The maximum uptake of ${ }^{18} \mathrm{~F}-$ deoxyglucose on positron emission tomography scan correlates with survival, hypoxia inducible factor-1alpha and GLUT-1 in non-small cell lung cancer. Eur J Cancer. 2007;43:1392-1398.

82. Kong FM, Frey KA, Quint LE, et al. A pilot study of $\left[{ }^{18} \mathrm{~F}\right]$ fluorodeoxyglucose positron emission tomography scans during and after radiation-based therapy in patients with non small-cell lung cancer. J Clin Oncol. 2007;25:3116-3123.

83. van Elmpt W, Ollers M, Dingemans AM, Lambin P, De Ruysscher D. Response assessment using ${ }^{18} \mathrm{~F}$-FDG PET early in the course of radiotherapy correlates with survival in advanced-stage non-small cell lung cancer. J Nucl Med. 2012;53:1514-1520.

84. van Baardwijk A, Bosmans G, Dekker A, et al. Time trends in the maximal uptake of FDG on PET scan during thoracic radiotherapy: a prospective study in locally advanced non-small cell lung cancer (NSCLC) patients. Radiother Oncol. 2007;82:145-152.

85. Edet-Sanson A, Dubray B, Doyeux K, et al. Serial assessment of FDG-PET FDG uptake and functional volume during radiotherapy (RT) in patients with non-small cell lung cancer (NSCLC). Radiother Oncol. 2012;102:251-257.

86. Minn H, Paul R, Ahonen A. Evaluation of treatment response to radiotherapy in head and neck cancer with fluorine-18 fluorodeoxyglucose. J Nucl Med. 1988;29:1521-1525.

87. Gupta T, Jain S, Agarwal JP, et al. Diagnostic performance of response assessment FDG-PET/CT in patients with head and neck squamous cell carcinoma treated with high-precision definitive (chemo)radiation. Radiother Oncol. 2010;97:194-199.

88. Marcus C, Ciarallo A, Tahari AK, et al. Head and neck PET/CT: therapy response interpretation criteria (Hopkins criteria) - interreader reliability, accuracy, and survival outcomes. J Nucl Med. 2014;55:1411-1416.

89. Yao M, Smith RB, Hoffman HT, et al. Clinical significance of postradiotherapy $\left[{ }^{18} \mathrm{~F}\right]$-fluorodeoxyglucose positron emission tomography imaging in management of head-and-neck cancer: a long-term outcome report. Int J Radiat Oncol Biol Phys. 2009;74:9-14.

90. Ceulemans G, Voordeckers M, Farrag A, Verdries D, Storme G, Everaert H. Can 18-FDG-PET during radiotherapy replace post-therapy scanning for detection/demonstration of tumor response in head-and-neck cancer? Int J Radiat Oncol Biol Phys. 2011;81:938-942.

91. Li C, Lan X, Yuan H, Feng H, Xia X, Zhang Y. ${ }^{18}$ F-FDG PET predicts pathological response to preoperative chemoradiotherapy in patients with primary rectal cancer: a meta-analysis. Ann Nucl Med. 2014;28:436-446.

92. Maffione AM, Chondrogiannis S, Capirci C, et al. Early prediction of response by ${ }^{18} \mathrm{~F}-\mathrm{FDG}$ PET/CT during preoperative therapy in locally advanced rectal cancer: a systematic review. Eur J Surg Oncol. 2014;40: 1186-1194.

93. de Geus-Oei LF, Vriens D, van Laarhoven HW, van der Graaf WT, Oyen WJ. Monitoring and predicting response to therapy with ${ }^{18} \mathrm{~F}$-FDG PET in colorectal cancer: a systematic review. J Nucl Med. 2009;50(suppl 1):43S-54S.

94. Schollaert P, Crott R, Bertrand C, D'Hondt L, Borght TV, Krug B. A systematic review of the predictive value of ${ }^{18}$ FDG-PET in esophageal and esophagogastric junction cancer after neoadjuvant chemoradiation on the survival outcome stratification. J Gastrointest Surg. 2014;18:894-905.

95. Palie O, Michel P, Ménard JF, et al. The predictive value of treatment response using FDG PET performed on day 21 of chemoradiotherapy in patients with oesophageal squamous cell carcinoma: a prospective, multicentre study (RTEP3). Eur J Nucl Med Mol Imaging. 2013;40:1345-1355.

96. Schwarz JK, Siegel BA, Dehdashti F, Grigsby PW. Association of posttherapy positron emission tomography with tumor response and survival in cervical carcinoma. JAMA. 2007;298:2289-2295.

97. Onal C, Reyhan M, Guler OC, Yapar AF. Treatment outcomes of patients with cervical cancer with complete metabolic responses after definitive chemoradiotherapy. Eur J Nucl Med Mol Imaging. 2014;41:1336-1342.

98. Kidd EA, Thomas M, Siegel BA, Dehdashti F, Grigsby PW. Changes in cervical cancer FDG uptake during chemoradiation and association with response. Int J Radiat Oncol Biol Phys. 2013;85:116-122.

99. Simoncic U, Jeraj R. Heterogeneity in stabilization phenomena in FLT PET images of canines. Phys Med Biol. 2014;59:7937-7955.

100. Muzi M, Mankoff DA, Grierson JR, Wells JM, Vesselle H, Krohn KA. Kinetic modeling of $3^{\prime}$-deoxy-3'-fluorothymidine in somatic tumors: mathematical studies. J Nucl Med. 2005;46:371-380.

101. Buck AK, Halter G, Schirrmeister $\mathrm{H}$, et al. Imaging proliferation in lung tumors with PET: ${ }^{18}$ F-FLT versus ${ }^{18}$ F-FDG. $J$ Nucl Med. 2003;44:1426-1431.
102. Chen W, Delaloye S, Silverman DH, et al. Predicting treatment response of malignant gliomas to bevacizumab and irinotecan by imaging proliferation with $\left[{ }^{18} \mathrm{~F}\right]$ fluorothymidine positron emission tomography: a pilot study. J Clin Oncol. 2007;25:4714-4721.

103. Herrmann K, Wieder HA, Buck AK, et al. Early response assessment using $3^{\prime}$-deoxy- $3^{\prime}-\left[{ }^{18} \mathrm{~F}\right]$ fluorothymidine-positron emission tomography in high-grade nonHodgkin's lymphoma. Clin Cancer Res. 2007;13:3552-3558.

104. Sugiyama M, Sakahara H, Sato K, et al. Evaluation of $3^{\prime}$-deoxy-3' ${ }^{\prime}{ }^{18}$ F-fluorothymidine for monitoring tumor response to radiotherapy and photodynamic therapy in mice. J Nucl Med. 2004;45:1754-1758.

105. Yang YJ, Ryu JS, Kim SY, et al. Use of $3^{\prime}$-deoxy- $3^{\prime}-\left[{ }^{18} \mathrm{~F}\right]$ fluorothymidine PET to monitor early responses to radiation therapy in murine SCCVII tumors. Eur J Nucl Med Mol Imaging. 2006;33:412-419.

106. Bradshaw TJ, Bowen SR, Deveau MA, et al. Molecular imaging biomarkers of resistance to radiation therapy for spontaneous nasal tumors in canines. Int $J$ Radiat Oncol Biol Phys. 2015;91:787-795.

107. Everitt S, Hicks RJ, Ball D, et al. Imaging cellular proliferation during chemoradiotherapy: a pilot study of serial ${ }^{18} \mathrm{~F}$-FLT positron emission tomography/ computed tomography imaging for non-small-cell lung cancer. Int J Radiat Oncol Biol Phys. 2009;75:1098-1104.

108. Hoeben BA, Troost EG, Span PN, et al. ${ }^{18}$ F-FLT PET during radiotherapy or chemoradiotherapy in head and neck squamous cell carcinoma is an early predictor of outcome. J Nucl Med. 2013;54:532-540.

109. Nyflot MJ, Kruser TJ, Traynor AM, et al. Phase 1 trial of bevacizumab with concurrent chemoradiation therapy for squamous cell carcinoma of the head and neck with exploratory functional imaging of tumor hypoxia, proliferation, and perfusion. Int J Radiat Oncol Biol Phys. 2015;91:942-951.

110. Trigonis I, Koh PK, Taylor B, et al. Early reduction in tumour $\left[{ }^{18} \mathrm{~F}\right]$ fluorothymidine (FLT) uptake in patients with non-small cell lung cancer (NSCLC) treated with radiotherapy alone. Eur J Nucl Med Mol Imaging. 2014;41:682-693.

111. Umbehr MH, Müntener M, Hany T, Sulser T, Bachmann LM. The role of ${ }^{11} \mathrm{C}$ choline and ${ }^{18} \mathrm{~F}$-fluorocholine positron emission tomography (PET) and PET/ CT in prostate cancer: a systematic review and meta-analysis. Eur Urol. 2013;64:106-117.

112. Nuutinen J, Sonninen P, Lehikoinen P, et al. Radiotherapy treatment planning and long-term follow-up with $\left[{ }^{11} \mathrm{C}\right]$ methionine PET in patients with low-grade astrocytoma. Int J Radiat Oncol Biol Phys. 2000;48:43-52.

113. Bradshaw TJ, Yip S, Jallow N, Forrest LJ, Jeraj R. Spatiotemporal stability of $\mathrm{Cu}-\mathrm{ATSM}$ and FLT positron emission tomography distributions during radiation therapy. Int J Radiat Oncol Biol Phys. 2014;89:399-405.

114. Koh WJ, Bergman KS, Rasey JS, et al. Evaluation of oxygenation status during fractionated radiotherapy in human nonsmall cell lung cancers using [F-18] fluoromisonidazole positron emission tomography. Int J Radiat Oncol Biol Phys. 1995;33:391-398.

115. Zips D, Zöphel K, Abolmaali N, et al. Exploratory prospective trial of hypoxiaspecific PET imaging during radiochemotherapy in patients with locally advanced head-and-neck cancer. Radiother Oncol. 2012;105:21-28.

116. Nyflot MJ, Kruser TJ, Traynor AM, et al. Phase 1 trial of bevacizumab with concurrent chemoradiation therapy for squamous cell carcinoma of the head and neck with exploratory functional imaging of tumor hypoxia, proliferation, and perfusion. Int J Radiat Oncol Biol Phys. 2015;91:942-951.

117. Li L, Yu J, Xing L, et al. Serial hypoxia imaging with ${ }^{99 \mathrm{~m}} \mathrm{Tc}-\mathrm{HL} 91$ SPECT to predict radiotherapy response in nonsmall cell lung cancer. Am J Clin Oncol. 2006;29:628-633.

118. Hoebers FJ, Kartachova M, de Bois J, et al. ${ }^{99 \mathrm{~m}} \mathrm{Tc}$ Hynic-rh-annexin V scintigraphy for in vivo imaging of apoptosis in patients with head and neck cancer treated with chemoradiotherapy. Eur J Nucl Med Mol Imaging. 2008;35:509518.

119. Mayr NA, Yuh WT, Magnotta VA, et al. Tumor perfusion studies using fast magnetic resonance imaging technique in advanced cervical cancer: a new noninvasive predictive assay. Int J Radiat Oncol Biol Phys. 1996;36:623-633.

120. George ML, Dzik-Jurasz AS, Padhani AR, et al. Non-invasive methods of assessing angiogenesis and their value in predicting response to treatment in colorectal cancer. Br J Surg. 2001;88:1628-1636.

121. Fuss M, Wenz F, Essig M, et al. Tumor angiogenesis of low-grade astrocytomas measured by dynamic susceptibility contrast-enhanced MRI (DSC-MRI) is predictive of local tumor control after radiation therapy. Int J Radiat Oncol Biol Phys. 2001;51:478-482.

122. Mardor Y, Roth Y, Ochershvilli A, et al. Pretreatment prediction of brain tumors' response to radiation therapy using high b-value diffusion-weighted MRI. Neoplasia. 2004;6:136-142.

123. Harry VN, Semple SI, Gilbert FJ, Parkin DE. Diffusion-weighted magnetic resonance imaging in the early detection of response to chemoradiation in cervical cancer. Gynecol Oncol. 2008;111:213-220. 
124. Hatakenaka M, Shioyama Y, Nakamura K, et al. Apparent diffusion coefficient calculated with relatively high b-values correlates with local failure of head and neck squamous cell carcinoma treated with radiotherapy. AJNR. 2011;32:19041910.

125. Eccles CL, Haider EA, Haider MA, Fung S, Lockwood G, Dawson LA. Change in diffusion weighted MRI during liver cancer radiotherapy: preliminary observations. Acta Oncol. 2009;48:1034-1043.

126. Kremser C, Judmaier W, Hein P, Griebel J, Lukas P, de Vries A. Preliminary results on the influence of chemoradiation on apparent diffusion coefficients of primary rectal carcinoma measured by magnetic resonance imaging. Strahlenther Onkol. 2003;179:641-649.

127. Zahra MA, Hollingsworth KG, Sala E, Lomas DJ, Tan LT. Dynamic contrastenhanced MRI as a predictor of tumour response to radiotherapy. Lancet Oncol. 2007;8:63-74.

128. Kim SY, Lee SS, Byun JH, et al. Malignant hepatic tumors: short-term reproducibility of apparent diffusion coefficients with breath-hold and respiratorytriggered diffusion-weighted MR imaging. Radiology. 2010;255:815-823.

129. Necib H, Garcia C, Wagner A, et al. Detection and characterization of tumor changes in ${ }^{18} \mathrm{~F}$-FDG PET patient monitoring using parametric imaging. $\mathrm{J} \mathrm{Nucl}$ Med. 2011;52:354-361.

130. Vera P, Dubray B, Palie O, et al. Monitoring tumour response during chemoradiotherapy: a parametric method using FDG-PET/CT images in patients with oesophageal cancer. EJNMMI Res. 2014;4:12.

131. Yip S, Chen AB, Aerts HJ, Berbeco R. Sensitivity study of voxel-based PET image comparison to image registration algorithms. Med Phys. 2014;41: 111714.

132. Hatt M, Majdoub M, Vallières M, et al. ${ }^{18} \mathrm{~F}$-FDG PET uptake characterization through texture analysis: investigating the complementary nature of heterogeneity and functional tumor volume in a multi-cancer site patient cohort. $\mathrm{J} \mathrm{Nucl}$ Med. 2015;56:38-44.

133. Bundschuh RA, Dinges J, Neumann L, et al. Textural parameters of tumor heterogeneity in ${ }^{18} \mathrm{~F}$-FDG PET/CT for therapy response assessment and prognosis in patients with locally advanced rectal cancer. J Nucl Med. 2014;55:891897.

134. Søvik A, Malinen E, Bruland ØS, Bentzen SM, Olsen DR. Optimization of tumour control probability in hypoxic tumours by radiation dose redistribution: a modelling study. Phys Med Biol. 2007;52:499-513.

135. Feng M, Kong FM, Gross M, Fernando S, Hayman JA, Ten Haken RK. Using fluorodeoxyglucose positron emission tomography to assess tumor volume during radiotherapy for non-small-cell lung cancer and its potential impact on adaptive dose escalation and normal tissue sparing. Int J Radiat Oncol Biol Phys. 2009;73:1228-1234.
136. Marks LB, Munley MT, Spencer DP, et al. Quantification of radiation-induced regional lung injury with perfusion imaging. Int J Radiat Oncol Biol Phys. 1997;38:399-409.

137. Robbins ME, Brunso-Bechtold JK, Peiffer AM, Tsien CI, Bailey JE, Marks LB. Imaging radiation-induced normal tissue injury. Radiat Res. 2012;177:449-466.

138. Partridge M, Yamamoto T, Grau C, Høyer M, Muren LP. Imaging of normal lung, liver and parotid gland function for radiotherapy. Acta Oncol. 2010;49:9971011.

139. Hart JP, McCurdy MR, Ezhil M, et al. Radiation pneumonitis: correlation of toxicity with pulmonary metabolic radiation response. Int J Radiat Oncol Biol Phys. 2008;71:967-971.

140. Mac Manus MP, Ding Z, Hogg A, et al. Association between pulmonary uptake of fluorodeoxyglucose detected by positron emission tomography scanning after radiation therapy for non-small-cell lung cancer and radiation pneumonitis. Int J Radiat Oncol Biol Phys. 2011;80:1365-1371.

141. De Ruysscher D, Houben A, Aerts HJ, et al. Increased ${ }^{18} \mathrm{~F}$-deoxyglucose uptake in the lung during the first weeks of radiotherapy is correlated with subsequent radiation-induced lung toxicity (RILT): a prospective pilot study. Radiother Oncol. 2009;91:415-420.

142. Cannon B, Schwartz DL, Dong L. Metabolic imaging biomarkers of postradiotherapy xerostomia. Int J Radiat Oncol Biol Phys. 2012;83:1609-1616.

143. Jingu K, Kaneta T, Nemoto K, et al. The utility of ${ }^{18} \mathrm{~F}$-fluorodeoxyglucose positron emission tomography for early diagnosis of radiation-induced myocardial damage. Int J Radiat Oncol Biol Phys. 2006;66:845-851.

144. Elicin O, Callaway S, Prior JO, Bourhis J, Ozsahin M, Herrera FG. $\left[{ }^{18}\right.$ F]FDGPET standard uptake value as a metabolic predictor of bone marrow response to radiation: impact on acute and late hematological toxicity in cervical cancer patients treated with chemoradiation therapy. Int J Radiat Oncol Biol Phys. 2014;90:1099-1107.

145. McGuire SM, Menda Y, Ponto LL, Gross B, Juweid M, Bayouth JE. A methodology for incorporating functional bone marrow sparing in IMRT planning for pelvic radiation therapy. Radiother Oncol. 2011;99:49-54.

146. Enslow MS, Zollinger LV, Morton KA, et al. Comparison of ${ }^{18} \mathrm{~F}$-fluorodeoxyglucose and ${ }^{18} \mathrm{~F}$-fluorothymidine PET in differentiating radiation necrosis from recurrent glioma. Clin Nucl Med. 2012;37:854-861.

147. Hatzoglou V, Ulaner GA, Zhang Z, Beal K, Holodny AI, Young RJ. Comparison of the effectiveness of MRI perfusion and fluorine-18 FDG PET-CT for differentiating radiation injury from viable brain tumor: a preliminary retrospective analysis with pathologic correlation in all patients. Clin Imaging. 2013;37:451-457.

148. Lizarraga KJ, Allen-Auerbach M, Czernin J, et al. ${ }^{18}$ F-FDOPA PET for differentiating recurrent or progressive brain metastatic tumors from late or delayed radiation injury after radiation treatment. $J$ Nucl Med. 2014;55:30-36. 